\title{
EL SER OCULTO DE LA CULTURA FEMENINA EN LA OBRA DE GEORG SIMMEL
}

\author{
Josetxo Beriain
}

Universidad Pública de Navarra

\section{RESUMEN}

El presente trabajo aborda el análisis de la "cultura femenina» en la obra de Simmel, tomando en consideración su carácter oculto dentro de la cultura objetiva, predominantemente masculina. Aspectos como el género, el amor y la sexualidad son considerados a la luz de las contribuciones realizadas por la crítica social contemporánea representada en los enfoques de Goffman, Foucault, Benhabib, Butler y Beck.

"Y creó Dios al ser humano a su imagen;

a imagen de Dios lo creó;

varón y hembra los creó.»

Génesis 1: 27

"¿No habéis leído aquello?

Ya al principio el creador los hizo varón y hembra.»

Jesús DE NAZARETH (Mat. 19: 4)

«Ecce homo (Aquí tenéis al hombre).» 
«Porque no procede el hombre de la mujer,

sino la mujer del hombre;

ni tampoco fue creado el hombre para la mujer,

sino la mujer para el hombre.

Sólo que en cristiano ni hay mujer sin el hombre

ni hombre sin la mujer,

pues lo mismo que la mujer (Eva) salió del hombre (Adán),

también el hombre nace por la mujer,

y todo viene de Dios.»

PABlo (I Cor. 11: 8-12)

"Aquí no puede valernos como ideal una "humanidad autónoma", que desde otro punto de vista ha sido caracterizada como el ideal del movimiento de las mujeres, sino una "femineidad autónoma", y ello ya porque en vista de la identificación histórica de lo masculino y lo humano aquella humanidad se mostraría, vista exactamente desde sus contenidos, como una masculinidad.»

Georg SimmeL

«Una no nace mujer sino que se hace mujer.»

Simone DE BEAUVOIR

«El género es una clase de imitación para la cual no hay original... El género no es un acto performativo que un sujeto previo decide ejecutar sino que es performativo en el sentido de que se constituye como un efecto de lo que expresa el sujeto en cuestión.»

Judith BUTLER

De los clásicos de la sociología, tanto europeos como norteamericanos, Georg Simmel es el único autor que reflexiona de forma expresa sobre la mujer. Su reflexión no se va a centrar tanto en la «cuestión social», es decir, en el análisis del movimiento social femenino burgués, en el que se podía englobar a Helene Lange, Gertrude Bäumer o Marianne Weber (esposa de Max Weber), o en el movimiento social femenino proletario, en el que destacan Rosa Luxemburgo o Emma Goldman, como en la "cuestión cultural»" es decir, en la representación social de lo femenino, en el universo simbólico que caracteriza a lo femenino dentro de una sociedad cuyo patrón (que no matriz) es masculino.

Para determinar los ejes de relevancia de la obra simmeliana en torno a la constelación femenina, el amor y la sexualidad, vamos a fijar inicialmente su

1 K. Lichtblau, Georg Simmel, Frankfurt, 1997, 104. 
punto de partida en torno a la correferencia entre las categorías de forma y contenido; en segundo lugar abordaremos la significación sociológica del «a priori sociocultural» de la vida considerada como movimiento del alma humana que se objetiva en formas que se independizan de ella; en tercer lugar analizaremos el Zeitdiagnose que permite a Simmel determinar la tragedia de la cultura moderna al escindirse entre cultura objetiva y cultura subjetiva; en cuarto lugar desvelaremos el patrón cultural fáctico sobre el que se sustenta la cultura objetiva: el masculino-patriarcal, así como la matriz contrafáctica femenina que constituye la alteridad de aquél; en quinto lugar realizaremos una descripción de la fenomenología social de tal "cultura femenina» subjetiva, y, finalmente, nos detendremos en el análisis del amor clásico y moderno.

Pero difícilmente podríamos comprender la naturaleza de la constelación femenina sin tener presente previamente la arquitectura conceptual simmeliana que le sirve como marco interpretativo en el cual adquieren sentido las diversas formas sociales. Así pues, vamos a distinguir cuatro conceptos fundamentales ${ }^{2}$ que recorren el corpus sociológico simmeliano.

\section{EL PUNTO DE PARTIDA SIMMELIANO: LA CORREFERENCIA ENTRE FORMA Y CONTENIDO COMO PROTOCATEGORÍAS DEL MÉTODO SOCIOLÓGICO}

Según el enfoque sociológico simmeliano, cuya primera expresión metodológica aparece en su Sociología (1908), el mundo se compone de innumerables contenidos a los que se da una determinada identidad, estructura y significado a través de la imposición de formas que el individuo ha creado en el curso de su experiencia ${ }^{4}$. El punto de partida de Simmel es la distinción entre forma y contenido. Los contenidos son aquellos aspectos de la existencia que están deter-

2 Ver al respecto los dos interesantes artículos de uno de los editores norteamericanos de la obra de Simmel: Donald N. Levine, "Some Key Problems in Simmel's Work», en L. Coser (ed.), Georg Simmel, Prentice Hall, NJ, 1965, 97-98, así como «The Structure of Simmel's Social Thought», en Georg Simmel et al., Essays on Sociology, Philosophy and Aesthetics, Nueva York, 1950, 19-24. También en la introducción a Georg Simmel. On Individuality and Social Forms, Chicago, 1971, xxxi y ss. Ver, asimismo, el artículo de B. Nedelman, "Georg Simmel», en D. Kaesler (ed.), Klassiker der Soziologie, vol. 1, Munich, 1999, 127-150.

3 Conjunto de escritos que no conforman en cuanto tales una unidad con un hilo conductor claramente delimitado, sino más bien una yuxtaposición de escritos elaborados durante los quince años anteriores, es decir, en la última década del siglo XIX y en la primera década del siglo XX, y que en buena medida han servido de referencia para que una buena parte de la recepción simmeliana etiquetara la obra de Simmel de sociología «formal». Esta Grossen Soziologie se completará con una Kleine Soziologie que aparecerá en 1917.

${ }^{4}$ Fijémonos en la semejanza existente entre este presupuesto simmeliano y la definición de cultura de Weber, según la cual: «la cultura es ese ámbito delimitado (de formas) de la infinitud (de contenidos) desprovista de sentido del acaecer universal al cual los seres humanos otorgamos valor y significado». Gesammelte Aufsätze zur Wissenschaftslehre, J. C. B. Mohr, Tubinga, 1988, 180. 
minados en sí mismos pero que en cuanto tales no tienen ni estructura ni la posibilidad de ser comprendidos por nosotros en su inmediatez. «En todo fenómeno social, el contenido y la forma sociales constituyen una realidad unitaria. La forma social no puede alcanzar una existencia si se la desliga de todo contenido; del mismo modo que la forma espacial no puede subsistir sin una materia de la que sea forma. Tales son justamente los elementos de todo ser y acontecer sociales: un interés, un fin, un motivo y una forma o manera de acción recíproca entre los individuos, por la cual o en cuya figura alcanza aquel contenido realidad social $»^{5}$. Las formas son principios sintéticos que seleccionan contenidos de la experiencia posible configurándolos como unidades determinadas. En este sentido las formas son idénticas a las categorías a priori del conocimiento de Kant, pero, sin embargo, difieren de ellas en dos aspectos importantes. Ellas in-forman no sólo el ámbito cognitivo ${ }^{6}$, y aquí radica la contribución de Simmel, sino todas las dimensiones de la experiencia humana. Tales formas no son fijas e inmutables, sino que emergen, se desarrollan y, quizás, desaparecen en el tiempo.

El imaginario social (la vida en los términos de Simmel) actúa como el reservorio de los contenidos, como el caos, como el abismo, como la alteridad y originación perpetua de alteridad que figura y se figura (es figurándose), es creación de «imágenes» que son como manifestaciones de significaciones ${ }^{7}$; pero el imaginario precisa de unas formas a través de las cuales pueda expresarse, ya que por sí mismo no lo puede hacer. Desde una perspectiva sociológica tales contenidos son necesidades, impulsos, propósitos que conducen a los individuos a actuar de una $u$ otra manera. Las formas son esos procesos sintéticos por los que los individuos se combinan en unidades supraindividuales como la díada, la tríada, la secta, la iglesia, el partido político, el sindicato, el Estadonación, que pueden ser estables o transitorias, solidarias o antagonistas, de dominadores o de dominados, de nativos o de extranjeros.

Ninguna cosa o evento tiene un significado intrínseco o fijo, dado, inmutable, sino que su significado emerge a través de la interacción con otras cosas o eventos. Las diversas esferas de lo real se constituyen por medio de relaciones de copertenencia, de co-implicación, entre el todo y las partes, entre lo sagrado y lo profano ${ }^{8}$, entre la riqueza y la pobreza ${ }^{9}$, entre el dominador y el subordinado $^{10}$, entre lo masculino y lo femenino ${ }^{11}$, entre el nativo y el extran-

5 G. Simmel, Sociología, Madrid, 1986, vol. 1, 17.

${ }^{6}$ Ámbito éste desde el que Kant sitúa lo que podemos conocer científicamente, el fenómeno, y aquello que no podemos conocer, la cosa en sí.

7 Ver la aportación de C. CASTORIADIS en su obra L'institution imaginaire de la société, París, 1975, 493 ss.

${ }^{8}$ Ver G. Simmel, «On the Sociology of Religion», incluido en Simmel on Culture, D. Frisby y M. Featherstone (eds.), Londres, 1997, 282.

${ }^{9}$ G. Simmel, Sociología, vol. 2, 479 ss.

${ }^{10}$ G. SimmeL, Sociología, vol. 1, 147 ss.

${ }^{11}$ G. SimmeL, Schriften zur Philosophie und Soziologie der Geschlechter (en adelante aparecerá citado este texto con la abreviatura SPSG), H.-J. Dahme y K. C. Köhnke (eds.), Frankfurt, 
jero $^{12}$, entre la oferta y la demanda ${ }^{13}$, etc. "Las relaciones crean las cosas, las relaciones existen antes que las cosas ${ }^{14}$. La influencia recíproca es la realidad a la que se refiere el término sociedad. Ésta no existe sino por «el hecho de que los hombres se influyan recíprocamente, de que uno haga o padezca, sea o se transforme porque otros existen, se manifiestan, obran o sienten»" ${ }^{15}$. La sociedad debe ser entendida no como la reunión accidental y anárquica de elementos independientes los unos de los otros, sino todo lo contrario, como el conjunto de elementos sociales relacionados unos con otros, en los encuentros, en las discusiones, en los intercambios, en los conflictos, en las competiciones, en las relaciones de trabajo, en las relaciones de poder, en las relaciones amorosas.

Las propiedades de las formas y los significados de las cosas son una función de las distancias relativas entre los individuos y entre los individuos y las cosas. Las formas culturales surgen cuando la unidad de la experiencia inmediata es cuestionada y una distancia se interpone entre el sujeto y el objeto; por ejemplo, entre el comprador y el objeto deseado. A partir de aquí, las formas culturales sirven no sólo para capacitar al sujeto para experimentar a los objetos de modo característico, sino también para situarse a una distancia característica de tales objetos. El «valor» de un elemento de hecho no se puede determinar sino por la distancia social que le separa de los otros.

Veamos esto a través de algunos ejemplos tomados de la propia reflexión simmeliana. En la esfera de la economía, la distancia se establece por medio del cambio, esto es, por medio de la actuación dual de limitaciones, impedimentos y renuncias ${ }^{16}$. Solamente sobre la base de la significación que tiene para nosotros lo que conseguimos con dificultades y por medio de sacrificios, experimentamos el valor específico de aquello que obtenemos sin dificultad alguna, como un regalo en un accidente feliz. El homo oeconomicus divide la unidad misteriosa de sus relaciones con las cosas en sacrificio y beneficio, impedimento y consecución, y tiende a olvidar que si no le fuera dado alcanzar su meta sin tener que superar aquellos impedimentos, ya no sería la misma meta ${ }^{17}$.

El extranjero, aquel «que viene hoy y se queda mañana» ${ }^{18}$, socava el ordenamiento espacial del mundo, la coordinación conquistada entre la cercanía moral y topográfica, el estar juntos de los amigos y la remota lejanía de los enemigos. El extranjero nos advierte de la presencia de la distancia, pero ¿de qué distancia se trata? El extranjero trae al círculo cualidades que no proceden

1985, 159 ss, 200 ss. En esta colección de 15 escritos se halla incluida toda la obra de Simmel relacionada con la constelación femenina: psicología femenina, movimientos feministas, amor, sexualidad, coquetería, moda, etc.

${ }_{12}$ G. Simmel, Sociología, vol. 2, 716 ss.

13 G. Simmel, Filosofía del dinero, Madrid, 1976, 49 ss.

${ }_{14}$ W. Ross, Nuestro imaginario cultural, Barcelona, 1992, 27.

15 G. Simmel, Sociología, vol. 1, 33.

16 G. Simmel, Filosofía del dinero, op. cit., 61.

${ }_{17}$ G. SimmeL, op. cit., 53.

18 Ver G. Simmel, Sociología, vol. 2, 716 ss. 
ni pueden proceder del círculo. "La unión entre la proximidad y el alejamiento, que se contiene en todas las relaciones humanas, ha tomado aquí una forma que pudiera sintetizarse de este modo: la distancia, dentro de la relación, significa que el próximo está lejano, pero el ser extranjero significa que el lejano está próximo» ${ }^{19}$. El extranjero está físicamente cercano mientras permanece espiritualmente remoto. Él trae consigo al círculo interno la proximidad, el tipo de diferencia y alteridad, que son anticipadas y toleradas sólo a distancia ${ }^{20}$. Como vemos, la distancia social y la distancia física no coinciden; dos personas pueden ocupar dos posiciones muy próximas en el espacio físico y, sin embargo, estar separadas por una vertiginosa distancia social. Los protagonistas de la celebre obra de D. H. Lawrence El amante de Lady Chatterly, es decir, Lady Chatterly y su amante, representan esta situación: la interacción amorosa que les une, reduciendo a cero la distancia física; sin embargo, tiene su réplica en la gran distancia social que existe entre ambos, pertenecientes a los dos polos opuestos de la pirámide de estratificación, la clase alta en el caso de Lady Chatterly y la clase baja en el caso de su amante.

Como mejor podemos entender el mundo, a juicio de Simmel, es en términos de conflictos y contrastes entre categorías opuestas. La condición de la existencia de cualquier aspecto de la vida es la coexistencia de elementos diametralmente opuestos. Algunas veces estas cualidades o tendencias tienen su origen en una unidad indiferenciada; por ejemplo, el tao como orden impersonal que aloja órdenes más personalizados como el Yang y el Yin en las religiones chinas, o como el amor, síntesis de posesión y de no posesión ${ }^{21}$; en otros casos, una forma es definida como síntesis de los opuestos o como punto intermedio entre ambos, como en el reparto de recursos determinado por el derecho en casos de separación matrimonial, en los repartos de herencias (en donde se trata de distribuir los recursos siempre escasos entre las partes litigantes); en otros casos, las formas son vistas como entidades que varían de modo inversamente proporcional, como cuando en el enriquecimiento de unos se adivina el empobrecimiento de otros, o en el predominio de la cultura masculina se advierte la subjerarquización de la cultura femenina. Para Simmel, el conflicto representa una fuerza integradora grupal $^{22}$; las hostilidades no sólo impiden que vayan poco a poco borrándose las diferencias dentro del grupo, sino que, además, son sociológicamente productivas. "Lo que en esta vida aparece inmediatamente como disociación, es, en realidad, una de las formas elementales de socialización ${ }^{23}$.

19 G. SiMMEL, op. cit., 716-717.

20 Z. Bauman, Modernity and Ambivalence, Londres, 1991, 60; ver, asimismo, el análisis crítico de la condición de extranjero de I. Chambers, en Migración, cultura e identidad, Buenos Aires, 1995.

${ }^{21}$ Ver G. Simmel, «Psychologie der Koketterie», en SPSG, op. cit., 187-199 (traducción parcial de los escritos anteriores en Cultura femenina y otros ensayos, Barcelona, 1999, 115-139).

${ }_{22}$ Ver G. Simmel, Sociología, vol. 1, especialmente los capítulos 3 y 4, dedicados a la subordinación y a la lucha, respectivamente, como formas de interacción social.

${ }^{23}$ G. Simmel, op. cit., 269, 271. Ver, sobre este aspecto, L. COSER, Las funciones del conflicto social, México, D.F., 1961. 
¿Cómo permanecer indiferentes ante el hecho de que entre hombres y mujeres, una aversión completamente elemental, e incluso un sentimiento de odio sin razones particulares, y provocado por simple repulsión mutua, es, a veces, el primer estadio de relaciones, cuyo segundo estadio es un amor apasionado?

\section{LA TRASCENDENCIA INMANENTE: VIDA VERSUS FORMA COMO CATEGORÍAS DE LA EXPERIENCIA HUMANA}

Un dualismo básico recorre la forma fundamental de todo tipo de socialidad. El dualismo consiste en el hecho de que una relación que es fluctuante, constantemente en proceso de desarrollo, nunca recibe una forma externa relativamente estable. Las formas sociológicas de la conducta recíproca, de unificación, de presentación hacia fuera, no pueden seguir con una precisa adaptación a los cambios en su interior, es decir, a los procesos que ocurren en el individuo en relación con el otro. Estas dos instancias, relación y forma, tienen diferentes tempi de desarrollo ${ }^{24}$. Nuestra vida interna, que percibimos como una corriente, como un proceso incesante, como un ir y venir de pensamientos, deviene cristalizado, incluso para nosotros mismos, en fórmulas y direcciones fijadas a menudo meramente por el hecho de que verbalizamos esta vida, es decir, permanece como un a priori de contrastes formales, fundamentales, entre el flujo esencial y el movimiento de la psique subjetiva y las limitaciones de sus formas (objetivadas).

Georg Simmel, al final de su vida, en 1918, en dos artículos de extraordinaria importancia ${ }^{25}$, nos ofrece las claves interpretativas desde las que adquieren sentido todas las categorías de la sociología «formal» que ya había diseñado en 1907 en su Soziologie. Según él, estamos situados ante una paradoja insalvable ${ }^{26}$ : por una parte, "más-vida» (Mehr-Leben), es decir, la necesidad de crear nuevas formas socioculturales, ya que precisamos de nueva "cultura objetiva", necesidad ésta acrecentada por la modernidad al autopostularse como «novedad de la novedad más nueva», como "expansión sin límite del dominio racional del mundo»; pero, por otra parte, tenemos que confrontarnos con «másque-vida» (Mehr-als-Leben), con la autonomización, con la autorreferencia, que adquieren nuestros productos una vez que han sido objetivados en su "ahí" social. Las creaciones humanas adquieren su propia alteridad, que se manifiesta como absoluta (con independencia de su creador, el hombre), como "más allá» del hombre, e incluso en algunos casos "en su contra», como nos lo ha puesto de manifiesto Marx. Los individuos son trascendidos por las formas por ellos/as

${ }^{24}$ The Sociology of Georg Simmel, K. Wolff (ed.), Nueva York, 1964, 385-386.

${ }_{25}$ Me refiero a las dos traducciones que componen este monográfico: «La trascendencia de la vida» $\mathrm{y}$ «El conflicto de la cultura moderna», ambas publicadas por primera vez en 1918 .

${ }_{26}$ G. Simmel, "Die Traszendenz des Lebens», contenido en Lebensanschauung, Berlín, (1918), 1994, 23 ss. (la traducción de este artículo forma parte del presente monográfico, dedicado al centenario de la aparición de la Filosofía del dinero). 
creadas (la cultura objetiva), pero, al mismo tiempo, la vida (la creatividad inscrita en el alma humana) trasciende las formas culturales cristalizadas en el seno de la conciencia colectiva ${ }^{27}$ creando nuevas formas. La vida en este sentido representa la acción de lo instituyente sobre lo instituido.

La vida, a través de su agencia dinámica, el alma humana ${ }^{28}$, extrae de su magma imaginario de contenidos, de su indeterminación de posibilidades, unas determinadas formas, unas constelaciones de sentido, se autolimita siendo ella misma sin-límite ("más-vida») al originar su alteridad, la forma, la objetividad. El modo de existencia que no restringe su realidad al momento presente, situando el pasado y el futuro en el ámbito de lo irreal, eso es lo que llamamos $v i^{29}$. La condición última metafísicamente problemática de la vida radica en que es continuidad sin límite y, al mismo tiempo, es ego determinado por sus formas limitadas. La vida empuja más allá de la forma orgánica, espiritual u objetiva de lo realmente existente y sólo por esta razón la trascendencia es inmanente a la vida ${ }^{30}$. La vida se revela a sí misma como un continuo proceso de autotrascendencia, proceso éste de autorrebasamiento que la caracteriza como unidad, como la unidad del panta rei heraclíteo, como el ser propio del devenir. En su extraordinario texto intitulado "Puente y Puerta», de 1909, Simmel inequívocamente ya había manifestado que "el hombre es el ser fronterizo que no tiene ninguna frontera ${ }^{31}$. Aquí, Simmel nos pone de manifiesto cómo el hombre crea su propio destino (como también apuntaba Weber), pero no un destino metasocialmente dado, más allá de su intervención, sometido a instancias suprasociales, como Dios o la naturaleza, sino un destino producido por él mismo, un destino que emerge en la correferencia entre ser y deber ser, decisión y resultados, libertad y dependencia; en definitiva, entre vida y forma.

Si la vida es apeiron, sin límite, la forma es peras, límite; si la vida -como fenómeno cósmico, social, psicológico, genérico, singular- es tal flujo continuo, existe una buena razón para su profunda oposición a la forma. Esta oposición aparece como una incesante batalla de la vida contra el patrón histórico de la forma social. La vida precisa de una forma (o, si se quiere, de una conformación); sin ella no se puede expresar, no se puede manifestar, pero la vida no se puede objetivar plenamente en la forma. Precisa de la forma pero trasciende a la forma ${ }^{32}$, porque la vida siempre es más que lo actualmente objetivado, realizado; abarca también lo «todavía no». El conflicto entre vida y forma se manifiesta en una gran variedad de fenómenos, como la tensión entre los

${ }^{27}$ Ver sobre esta idea el trabajo de Deena Weinstein y Michael A. Weinstein, «Simmel and the Theory of Postmodern Society", recogido en B. S. Turner (ed.), Theories of Modernity and Postmodernity, Sage, Londres, 1990, 75-87.

${ }^{28}$ G. Simmel, Sociología, vol. 1, 31, 33.

29 G. Simmel, «Die Transzendenz...», op. cit., 12.

${ }^{30}$ G. Simmel, op. cit., 13.

${ }^{31}$ Escrito recogido en la compilación de artículos de G. SIMMEL intitulada El individuo y la libertad, Barcelona, 1986, 34.

32 G. Simmel, «Die Traszendenz...», op. cit., 22. 
objetivos del científico individual y la división del trabajo científico, en la discrepancia entre la experiencia religiosa auténtica y las instituciones eclesiásticas a las que esta experiencia debe acomodarse, o en la lucha entre la integridad de la expresión artística y las formas estéticas en las que el artista es obligado a objetivar su trabajo. "Así como el trascender de la vida más allá de su actual forma determinada dentro del plano de la vida misma constituye el más-vida, que es, sin embargo, el núcleo inmediato e inescapable de la vida, así su trascender dentro del nivel del contenido objetivo, del significado que es lógicamente autónomo y ya nunca más vital, constituye el más-que-vida... Esto no significa otra cosa que la vida no es vida solamente, aunque tampoco es otra cosa que vida» ${ }^{33}$. Aunque con distintos énfasis, esto se ha puesto de manifiesto en la historia de la moderna reflexión sociológica; así, en la potencialidad innovadora de la dominación carismática actuando como fermento de cambio social descrita por Max Weber, en la no menos innovadora repercusión de la división del trabajo descrita por Émile Durkheim, o en el incremento de las fuerzas productivas descrito por Karl Marx como fuerza social invisible, o en las innúmeras variedades de acción social creativa estudiadas por Hans Joas y Charles Tilly, o en la actuación de la dimensión instituyente de la sociedad sobre su dimensión instituida como lo ha puesto Cornelius Castoriadis, y aún podríamos continuar con un sinfín de ejemplos al respecto.

Las formas sociales adquieren autonomía en relación a los impulsos momentáneos y a las demandas inmediatas de la vida de dos maneras. La primera es a través de estructuras institucionalizadas (Gebilde) como la familia, la iglesia, la universidad, el parlamento, el ejército, la fábrica, el cine, el supermercado, la calle, el teatro, la autopista, etc., que representan una objetivación (Vergegenständigung) de las formas. Para que estas formas estén disponibles transpersonalmente es preciso que una acción creativa exteriorice unos signos y unos símbolos que son "transgresivos" ${ }^{34}$, por cuanto que franquean la frontera entre lo interno (individual) y lo externo (social) y se sitúan en un plano de evidencia social, es decir, "están ahí». La función característica de las instituciones (formas) es la descarga-exoneración (Entlastung) ${ }^{35}$ de las motivaciones subjetivas y de las improvisaciones frente a determinadas decisiones y programas de acción, es decir, las instituciones constituyen un umbral de tipificación cultural que opera con arreglo al principio de que: «así se hace; por tanto, así lo hacemos nosotros ${ }^{36}$. Debido a la indeterminación instintual del ser humano, a diferencia del animal, instintualmente rico, cada cultura extrae de la mul-

33 G. Simmel, «Die Traszendenz...», op. cit., 24. Ver, asimismo, dos interesantes interpretaciones recientes de este asunto: P.-O. UlLRICH, Inmanente Traszendenz. Georg Simmels Entwurf einer nach-christlichen Religionsphilosophie, Frankfurt, 1981, y H. JOAS, «Die Inmanenz der Traszendenz», en Die Entstehung der Werte, Frankfurt, 1997, 110-133.

${ }^{34}$ Ver al respecto la obra de E. Neumann, Die Psyche als Ort der Gestaltung, Frankfurt, 1992, 10.

35 Ver al respecto la obra de A. GeHLEN, Urmensch und Spätkultur, Wiesbaden, 1986, 23.

36 Th. LuCKMann, Theorie des Sozialen Handelns, Berlín, 1992, 146. 
tiplicidad de posibles modos de conducta humana ciertas variables y las exige en modelos conductuales, aprobados por la sociedad y obligatorios para todos los individuos que la componen. Estos modelos conductuales o instituciones exoneran al individuo de un exceso de decisiones, constituyen una guía para las innumerables impresiones y excitaciones que circundan al ser humano abierto al mundo. A la pregunta sobre cómo puede estabilizarse la conducta humana que es instintualmente limitada y, sin embargo, culturalmente ilimitada (en su apertura al mundo), la respuesta de Gehlen es con un «estar-ya-comprendidos», con el recurso a una precomprensión inscrita en las formas simbólicas que evitan la constante necesidad de experimentar la novedad más nueva con arreglo al esquema operativo de ensayo y error ${ }^{37}$. La segunda manera que sirve a las formas para separarse de la vida, del flujo vital, es transformando la objetivación previa (Vergegenständigung) en la autonomización (Verselbständigung), según la cual las formas se rigen con arreglo a su propia lógica, autorreferencialmente, con independencia de las voluntades individuales, de otras formas y de la vida en cuanto tal. Aquí también se inscriben las críticas de Marx al fetichismo de la mercancía, de Weber a la máquina burocrática, o de Habermas a los medios de comunicación simbólica generalizada (véase el dinero y el poder). Pero vamos a ver con un poco más de atención cuál es el significado de este proceso de objetivación y su correlato de autonomización como consecuencia involuntaria de aquél en su inserción en el diagnóstico de la época moderna que va a realizar Simmel.

\section{LA CRISIS DE LA CULTURA MODERNA}

El proceso en el que la vida primero se reproduce a sí misma como «másvida" y entonces se trasciende a sí misma generando formas que cualifican como «más-que-vida» nos sirve para tematizar el dominio de la cultura. Para Simmel, la cultura representa un proceso bidimensional ${ }^{38}$. Por una parte, las energías e intereses de la vida son definidos y moldeados por las formas de la "cultura objetiva»; el mundo de las formas culturales y sus artefactos se hacen independientes de la existencia individual. La cultura objetiva es el ámbito de los objetos que funcionan como instrumentos para cultivar a la persona o como las condiciones bajo las cuales el/ella pueda constituirse como ser cultural. Por otra parte, estas formas culturales y sus artefactos son incorporados en la «cultura subjetiva» del individuo, en la personalidad, que es el resultado último del proceso de cultivación y que representa una síntesis del mundo de las formas culturales. La cultura alude a ese proceso de cultivación ${ }^{39}$ de los indivi-

37 También ha tratado este aspecto con, sin duda, gran acierto G. H. MEAD en su obra maestra: Espiritu, persona y sociedad, Barcelona, 1982.

${ }^{38}$ Ver G. Simmel, "De la esencia de la cultura», en El individuo y la libertad, Barcelona, 1986, 119-127.

39 Ver G. Simmel, «El concepto de cultura», en Filosofía del dinero, Madrid, 1977, 560 ss. y 568-569. 
duos por medio de la agencia de las formas externas que han sido objetivadas en el curso de la historia. La cultivación es ese proceso de desarrollo de un individuo que: 1) no lo lograría de forma natural, pero 2) para el que tiene una propensión natural, 3) por la utilización de objetos externos a él. Las plantas y los animales pueden ser cultivados, pero el impulso para hacerlo surge fuera de ellos; por contraste, la obligación y capacidad para una cultivación completa están inseparablemente vinculadas al alma humana ${ }^{40}$. La cultura surge cuando se reúnen los dos elementos, ninguno de los cuales la contiene de por sí: el alma subjetiva y el producto espiritual objetivo. La cultura en sentido propio (es decir, subjetivo) existe sólo en la presencia del autodesarrollo de un centro psíquico, habida cuenta de que tal autodesarrollo descansa en medios externos, objetivos. Pero el ejercicio de las fuerzas creativas de la vida quedaría bloqueado si las estructuras de la cultura fueran completamente independientes de las personas cuya actividad es responsable de su producción. Por tanto, la completa emancipación de la cultura objetiva de su génesis subjetiva es imposible. Idealmente, el individio debiera ser capaz de absorber todos los elementos de la cultura objetiva en la cultura subjetiva, pero el proceso de modernización conlleva la separación entre ambas culturas. El alcance y la complejidad de la cultura objetiva se incrementa de tal manera que ya no es posible para el individuo apropiarse la cultura objetiva como un todo e integrar sus elementos en la experiencia subjetiva. Ésta es la tragedia de la modernidad, a juicio de Simmel ${ }^{41}$.

La relación peculiar que se establece en la modernidad entre la sustancia objetiva de la cultura y la cultura subjetiva de los individuos presenta para Simmel una serie de problemas, entre los que podemos destacar tres.

En primer lugar, los fines de la vida se subordinan a sus medios, con el resultado inevitable de que muchas cosas que son sólo medios adquieren el estatus psicológico de fines ${ }^{42}$. Simmel llama a esto configuración de los valores en una secuencia teleológica, en donde el fin deviene medio que, a su vez, es medio de otro medio, y así sin fin. En esta secuencia el nexo intermedio, instrumental, se multiplica hasta el final de la secuencia con el resultado de que los valores instrumentales reemplazan a los valores auténticos, los medios devienen fines. :Acaso no es necesario no darse por satisfecho, en la modernidad, con cada fin último hacia el que conduce nuestra actividad, sino buscar en cada uno una justificación posterior para otro que vaya más allá? De aquí resulta que ninguna ventaja o situación alcanzadas proporciona la satisfacción definitiva, que se vincula, lógicamente, con el concepto del fin último, sino que en

${ }^{40}$ Ver G. Simmel, «El concepto y la tragedia de la cultura», en Sobre la aventura. Ensayos filosóficos, Barcelona, 1988, 208, 209.

${ }_{41}$ Ver L. VAN VuCht TijssEN, «Women and Objective Culture: Georg Simmel and Marianne Weber", en Theory, Culture and Society, 1991, vol. 8, 203-218 (incluido en Georg Simmel Critical Assessments, D. Frisby, ed., Londres, 1994, 19-31).

${ }^{42}$ Ver G. Simmel, «Die Krisis der Kultur», en Der Krieg und die geistigen Entscheidungen. Reden und Aufsätze, Munich, 1917. 
realidad todo punto alcanzado únicamente es el estadio de transición hacia uno definitivo que se halla más allá de éste. "Los órdenes teleológicos, en la medida en que se orientan hacia lo posible en la tierra, por razón no sólo de su realización, sino también de su estructura interna, no pueden detenerse, y en lugar del punto fijo que cada uno de ellos parece poseer en su fin último, éste aparece únicamente como el principio heurístico y regulativo, según el cual no se puede considerar un solo objetivo volitivo como lo último, puesto que cada uno de éstos tiene abierta la posibilidad de convertirse en escalón para uno más elevado» ${ }^{43}$.

En la cultura occidental de la antigüedad clásica tardía, la mayor contribución del cristianismo fue resolver el problema del significado de la vida creado por la creciente instrumentalización de la cultura ${ }^{44}$. Esto se consiguió situando el propósito incondicional y el significado último de la vida en la salvación del alma y en el reino de Dios, que ocupó el estatus de los valores auténticos, trascendiendo todos los contenidos individuales, fragmentarios y sin significado de la vida. La idea de Dios encuentra su esencia más profunda en el hecho de que toda la diversidad y las contradicciones del mundo alcanzan la unidad en Él, puesto que es, de acuerdo con la bella expresión de Nicolás de Cusa, la coincidentia oppositorum $^{45}$. La agudeza analítica de Simmel le lleva incluso a sostener, no sin ironizar sobre el papel de su propio grupo étnico, los judíos, que «la capacidad especial y el interés de los judíos por los negocios dinerarios se han puesto en relación con su "educación monoteísta", esto es, un carácter nacional acostumbrado desde hace milenios a un ser superior unitario - especialmente debido a que la nación tenía sólo una relativa trascendencia- y a ver en él el objetivo y el punto de contacto de todos los intereses individuales, por lo que, asimismo, en la esfera económica es necesario que se dé el valor que aparece como la unidad omnicomprensiva y el punto en que se agudizan todos los órdenes internacionales $»^{46}$.

Sin embargo, Simmel es consciente de que la capacidad del cristianismo para crear valores auténticos (o nuevos imaginarios centrales, en los términos de Castoriadis) ha disminuido. En la modernidad, la ausencia de algo definitivo en el centro de la vida empuja a buscar una satisfacción momentánea en excitaciones, sensaciones y actividades continuamente nuevas, lo que nos induce a una falta de quietud y tranquilidad que se puede manifestar como el tumulto de la gran ciudad, como la manía de los viajes, como la lucha despiadada contra la competencia, como la falta específica de fidelidad moderna en las esferas del gusto, los estilos, los estados de espíritu y las relaciones ${ }^{47}$. El

${ }^{43}$ G. Simmel, Filosofia del dinero, Madrid, 1977, 271.

${ }_{44}$ Ver G. Simmel, Goethe. Kant y Goethe: Para una historia de la concepción moderna del mundo, Buenos Aires, 1949, 263 ss.; Schopenhauer und Nietzsche: Ein Vortragzyklus, Frankfurt, 1995.

${ }^{45}$ Ver G. Simmel, Filosofía del dinero, op. cit., 273.

${ }^{46}$ G. Simmel, op. cit., 273.

${ }^{47}$ Ver al respecto el magnífico artículo de Simmel intitulado «Las grandes urbes y la vida del 
dinero, símbolo de la unidad indescriptible del ser (social), se encuentra, por un lado, en el mismo orden que todos los otros medios e instrumentos de la cultura, es decir, el dinero es medio entre otros medios; pero, por otro lado, sin embargo, trasciende esta serie heterárquica (igualitaria) de medios, ya que es el intermediario a través del cual se producen los órdenes finales particulares. «El dinero es, antes que nada, un medio para todo, los contenidos de la existencia se incorporan, así, a una interminable conexión teleológica en la cual ninguno es el primero y ninguno es el último... Mide todas las cosas con objetividad despiadada y la mediación así establecida, determina sus vinculaciones ${ }^{48}$. Y esto no lo consigue a la manera del fundamento ontoteológico de la metafísica —el ser, Dios, motor inmóvil—, por medio de la quietud, la inmutabilidad, sino como actus purus, como perpetuum mobile. Anecdóticamente, apunta Simmel que la redondez de las monedas, en función de la cual éstas «tienen que rodar", simboliza el ritmo del movimiento que el dinero imprime a la circulación. El dinero, en su conjunto, se experimenta en su calidad de fin y, con ello, una gran cantidad de cosas que en realidad tienen el carácter de fines, por sí mismas, pasan a ser meros medios. Kenneth Burke expresa esto con una brillantez y profundidad incomparables al afirmar que el dinero funge como «un sustituto técnico de Dios, donde Dios representa la sustancia unitaria en la que se fundamenta toda diversidad de motivos... [el dinero pone en peligro a la religión] no en la forma dramática o agonística de un temperamento, sino en su forma sosegada racional, como un sustituto que realiza su rol mediador más eficientemente, con más parsimonia, con menos derroche de emociones que la concepción religiosa o ritualista del trabajo ${ }^{49}$. También Niklas Luhmann dedica un valioso comentario al dinero, considerándolo como «el que pone medida en todas las cosas, y en cierta forma es el medio de cuanto hay en el universo; él lo mide, compara, reduce a igualdad y proporción lo desigual y desconectado, de suerte que se puede decir que es mensura de la vida de los hombres» ${ }^{50}$. En el enfoque simmeliano, el dinero no es realmente un valor cultural auténtico; sólo parece ocupar este estatus en la conciencia de una cultura reificada e instrumentalizada. El valor sustancial del dinero no es otra cosa que su valor funcional; el dinero no solamente tiene una función, sino que es una función ${ }^{51}$. No existe un medio de comunicación simbólica generalizada más perfecto que el dinero, en donde se manifieste de forma más completa la inversión teleológica apuntada arriba.

Para corroborar lo dicho, déjeme el lector/a ofrecer un ejemplo tomado de la literatura donde aparece tipificada con gran claridad esta omnipresencia dia-

espíritu", incluido en El individuo y la libertad, Barcelona, 1986, 247-263. El análisis de Simmel de la multiplicidad de formas culturales coincide aquí con la concepción weberiana del politeísmo de valores.

${ }^{48}$ G. Simmel, Filosofía del dinero, op. cit., 539.

49 K. BURKE, A Grammar of Motives, Berkeley, 1962, 111-112.

${ }^{50}$ N. Luhmann, Die Wirtschaft der Gesellschaft, Frankfurt, 1988, 240.

${ }^{51}$ G. Simmel, Filosofía del dinero, op. cit., 175-176. 
bólica del dinero. Éste es uno de los temas más importantes en la primera gran novela de Thomas Mann, Los Buddenbrook (1909), en la tercera parte, en donde Tony Buddenbrook, la desconcertada princesa de la saga comercial del mismo nombre, se pregunta sobre el verdadero significado de la palabra «arruinado", siendo consciente de que las aventuras comerciales de su marido (Bendix Grünlich) se han acabado. En ese momento todo lo que conllevaba la palabra «bancarrota» emerge de repente ante ella, todas las vagas y temerosas insinuaciones que de niña había oído se hacen realidad. "Bancarrota», algo más vergonzoso que la muerte, era realmente la catástrofe, la ruina, la vergüenza, la desgracia, la miseria, el deshonor, la desesperación ${ }^{52}$. La bancarrota, o privación financiera total, es vivida como la pérdida total de valor, el fundamento axiológico cero; una relación que, por supuesto, presupone que el dinero ocupa el estatus del valor cultural paradigmático ${ }^{53}$. En los términos de Weber y de Sombart, podríamos decir que en el capitalismo desarrollado el dinero se ha convertido en el fin supremo al haberse evaporado el espíritu religioso que lo retenía como puro medio.

El segundo problema que detecta Simmel en la cultura de las sociedades modernas es que los productos objetivos de la cultura se desarrollan independientemente de sus creadores, según normas puramente objetivas que hacen referencia a sí mismas ${ }^{54}$. Por medio de la actividad de diferentes personas surge un objeto cultural que, en tanto que todo, en tanto que unidad que está ahí y que actúa específicamente, no tiene ningún productor, no ha surgido a partir de una correspondiente unidad de un sujeto anímico ${ }^{55}$. A causa de la inadecuación entre las formas de existencia del trabajador y de su producto, cada vez mayor a medida que aumenta la especialización, el último se separa totalmente y con gran facilidad del primero; su sentido no procede ya del espíritu de aquél, sino de su conexión con otros productos, originados en otras partes, y, debido a su carácter fragmentario, le falta la esencia de su espiritualidad, que, de otro modo, se atribuye directamente al producto del trabajo, en cuanto aparece en su totalidad como resultado de la labor de un ser humano. Así, este producto sólo puede encontrar su significación en su apartamiento del sujeto. Ocurre que habiéndonos emancipado del destino, de la fortuna y de la providencia, es decir, de formas religiosas, sin embargo, en la modernidad no nos hemos emancipado de aquel otro destino ${ }^{56}$, socialmente manufacturado, que

52 Ver Th. MAnN, Los Buddenbrook, Barcelona, 1993, tercera parte. Para la ubicación histórica de esta obra y de su saga, ver la obra de P. DE Mendelssohn, Der Zauberer. Das Leben des deutschen Sriftstellers Thomas Mann, Munich, 1975, vol. 1, 259 ss.

${ }_{53}$ Para ver la relación entre el dinero y la instrumentalización de la cultura, consultar la Filosofía del dinero, op. cit., capítulo tercero, segunda parte.

${ }_{54}$ Ver al respecto la interesante investigación de B. GIESEN, Die Entdinglichung des Sozialen, Frankfurt, 1991, especialmente "La autonomización de las estructuras simbólicas», 83-145.

55 Ver G. Simmel, «El concepto y la tragedia de la cultura», op. cit., 223.

56 Ver G. SIMMEL, "El futuro de nuestra cultura» y "El problema del destino», en El individuo y la libertad, Barcelona, 1986, 129, 39. Sobre el concepto de destino en las sociedades modernas avanzadas, ver J. BERIAIN, «Genealogía de la contingencia: del destino dado metaso- 
procede de la objetivación de nuevas formas sociales autonomizadas como la ciencia y la tecnología, el mercado, la burocracia, el consumo de masas, la moda, la ciudad, la fábrica. La división del trabajo aparece como causa y también como consecuencia de la creciente separación que se da en la sociedad moderna entre cultura objetiva y cultura subjetiva, entre cosas y personas. Supongamos que $\mathrm{O}$ representa un determinado estadio de objetivación de la cultura y $\mathrm{D}$ designa un determinado nivel de división del trabajo. Si t designa

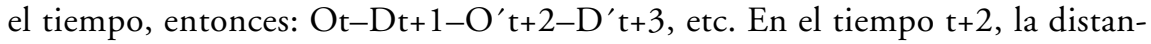
cia entre la cultura subjetiva y objetiva es mayor que en t. Así, la cultura de $\mathrm{O}^{\prime}$ está más objetivada que la cultura de O. Y, correlativamente, la cultura de $\mathrm{D}^{\prime}$ está más especializada y altamente diferenciada que la cultura de $\mathrm{D}^{57}$.

En el capítulo sexto de la Filosofía del dinero, Simmel examina la relación existente entre la objetivación y la división del trabajo considerando las condiciones de producción y consumo de artefactos culturales en una cultura avanzada. Si bien el interés de Marx, en la explicación de la génesis y el desarrollo del proceso capitalista de producción, se ha centrado en las relaciones sociales de producción, sin embargo, el interés prioritario de Simmel radica en las relaciones de consumo y de intercambio ${ }^{58}$ como ámbito más actualizado en donde se produce la comparecencia asimétrica de la cultura subjetiva y la cultura objetiva. Por esta razón, para Simmel, la conversión del trabajo en mercancía (el fetichismo de la mercancía en los términos de Marx) es únicamente un aspecto del amplio proceso de diferenciación que separa los contenidos aislados de la personalidad, a fin de situarlos enfrente de ella como objetos, con determinación y movimiento propios ${ }^{59}$. El mundo objetivado de las formas culturales y de sus artefactos, los productos de la producción de masas, crean una pseudocultura subjetiva en la que la personalidad de un consumidor es cualitativamente indistinguible de la de cualquier otro.

El tercer problema que advierte Simmel en la cultura moderna está relacionado con el desplazamiento de las viejas formas por nuevas, es decir, por el movimiento de creación sin fin procedente de la vida. En el presente estamos experimentando una nueva fase de la vieja lucha, no una lucha de una forma contemporánea, repleta de vida, contra una vieja forma, sin vida, sino una lucha de la vida contra la forma en cuanto tal, contra el principio de la forma. Moralistas, integristas de viejo y nuevo cuño y una parte respetable de gente

cialmente al destino producido socialmente», en R. RAMOS y F. GARCÍA SELGAS, Globalización, reflexividad y riesgo, Madrid, 1999.

57 Ver al respecto la Introducción de G. OAKES a Georg Simmel: On Women, Sexuality and Love, New Haven, Connecticut, 1984, 20; y, también, D. FRISBY, Sociological Impresionism, Londres, 1981, 123-124.

58 Ver José M. ${ }^{a}$ GONZÁlez GarCía, "Georg Simmel: el impresionismo en la sociología», en E. LAmo de Espinosa, J. M. a GonzÁlez y C. Torres, La sociología del conocimiento y de la ciencia, Madrid, 1994, 254 ss. Este análisis de Simmel será retomado en la crítica de la cultura de masas realizada por la Escuela de Frankfurt, especialmente por la Dialéctica de la Ilustración de Adorno y Horkheimer y por los Passagen-Werk de Benjamin.

59 Ver G. Simmel, Filosofía del dinero, 575; «El concepto y la tragedia de la cultura», 225. 
llevan razón cuando protestan contra la creciente "falta de forma» en la vida moderna $^{60}$. Quizás esta nueva constelación «sin-forma» sea el modo más apropiado de caracterizar la vida contemporánea. Cornelius Castoriadis se manifiesta en términos semejantes cuando afirma que «el desarrollo histórico y social consiste en salir de todo estado definido, en alcanzar un estado que no está definido por nada, salvo por la capacidad de alcanzar nuevos estadios. $L a$ norma es que no exista norma. El desarrollo histórico-social es un despliegue indefinido, sin fin ${ }^{61}$. En las ilusiones, en las imágenes de ensueño, y en las utopías del siglo XIX, en las que se manifiesta una dialéctica de «lo más nuevo y siempre lo mismo", se extiende, a juicio de Walter Benjamin, la protohistoria de la modernidad. La imagen de la modernidad «no se conduce con el hecho de que ocurre siempre la misma cosa (a fortiori, esto no significa el eterno retorno), sino con el hecho de que en la faz de esa cabeza agrandada llamada tierra lo que es más nuevo no cambia; esto "más nuevo" en todas sus partes permanece siendo lo mismo. Constituye la eternidad del infierno y su deseo sadista de innovación. Determinar la totalidad de las características en las que esta "modernidad" se refleja a sí misma significaría representar el infierno»" ${ }^{62}$ En la imagen del infierno como una configuración de repetición, novedad y muerte, Benjamin abrió a la comprensión filosófica el fenómeno de la moda, que es específico de la modernidad capitalista. Arnold Gehlen, en su obra maestra de interpretación sociológica, Urmensch und Spätkultur (1956), introduce un nuevo término, la "desinstitucionalización", paralelo al concepto simmeliano de "sin-forma». Según él, las instituciones arcaicas tienen un amplio alcance y son altamente estables, aproximándose así a las funciones de los instintos biológicos; consecuentemente, proveen un sentido de rutina; sin embargo, la modernidad "desinstitucionaliza», por cuanto que socava la estabilidad de las instituciones, reduce su alcance y abre así un amplio horizonte inmediato en el que la acción es el resultado de la racionalidad reflexiva.

\section{LA OTRA CULTURA: LA CULTURA FEMENINA}

Con la excepción de unas pocas áreas, nuestra cultura objetiva es predominantemente masculina. Son los hombres quienes han creado el arte y la industria, la ciencia y el comercio, el Estado y la religión. La creencia de que existe una cultura puramente «humana», para la que la diferencia entre el hombre y la mujer carece de relevancia, tiene su origen en la misma premisa de la que se sigue que tal cultura no existe: la identificación ingenua de lo "humano" con el «hombre»; incluso muchos lenguajes usan la misma palabra para ambos con-

${ }^{60}$ Ver G. Simmel, «Der Konflikt der modernen Kultur», en Das individuelle Gesetz, Frankfurt, 1987, 150, 173.

${ }^{61}$ C. Castoriadis, «Reflections sur le developement et la rationalité», en Domaines de l'Homme, París, 1987, 146.

${ }_{62}$ W. Benjamin, Passagen-Werk, Frankfurt, 1983, vol. 2, 1011. 
$\operatorname{ceptos}^{63}$. La cultura humana comparece como cultura del hombre. Determinadas categorías sociales se presentan como algo dado, natural, «olvidando» su construcción y génesis sociales. La posición de poder ocupada por el varón en la sociedad lleva a ecualizar lo objetivo y lo masculino (objetivo=masculino). El mundo instituido de significado expresa un consenso basado en la facticidad histórica de un hecho social, la impregnación de lo objetivo por lo masculino; pero no expresa un consenso plausible y legítimo, el de la existencia de dos totalidades o constelaciones de sentido, la masculina y la femenina. Establecemos la productividad y la naturaleza de la esencia masculina y femenina según normas determinadas por tales constelaciones, pero tales normas no son neutrales ni ajenas al antagonismo de géneros, sino que son en sí mismas manifestación de la masculinidad ${ }^{64}$.

El hecho de que los contenidos objetivos de nuestra cultura exhiban un carácter masculino, más que su carácter aparentemente neutral, se basa en un entrelazamiento polifacético de motivos históricos y psicológicos ${ }^{65}$. Sobre el valor de lo masculino y de lo femenino no decide una idea de valor neutral, sino la masculina. La confusión de los valores masculinos con los valores en general tiene su explicación en relaciones históricas del poder, es decir, en algo socialmente construido. Estas relaciones se expresan, lógicamente, en el funesto doble sentido del concepto de lo "objetivo»: lo objetivo aparece como la idea puramente neutral, equidistante de las unilateralidades masculino-femeninas; pero, sin embargo, lo "objetivo» es también la forma particular de la realización que corresponde a la forma de ser específicamente masculina. Lo primero representa una idea de carácter abstracto, suprahistórico y suprapsicológico; lo segundo representa una figura histórica que procede de la masculinidad diferenciada ${ }^{66}$. Como diría Michel Foucault, la genealogía de las interpretaciones se hace necesaria en el momento en que lo natural (lo humano - masculino- que representa lo objetivo) deviene socialmente construido ${ }^{67}, y$, sin duda, una parte

${ }^{63}$ Ver G. SimmEL, «Weibliche Kultur», en SPSG, Frankfurt, 1985, 161 (traducción castellana: Cultura femenina y otros ensayos, Barcelona, 1999, 177).

${ }^{64}$ Ver G. SimmeL, "Das Relative und das Absolute im Geschlechter-Problem», en SPSG, 200-201 (Cultura femenina..., 73-74).

${ }^{65}$ Ver al respecto P. Bourdieu, La domination masculine, París, 1998.

${ }^{66}$ Ver G. Simmel, «Weibliche Kultur», op. cit., 161-162 (Cultura femenina..., 189-190).

${ }^{67} \mathrm{M}$. FOUCAULT introduce una interesante reflexión relacionada con el concepto de posición o de interpretación. Dice así: «Si la interpretación fuera una lenta exposición del significado oculto en algún origen, entonces sólo la metafísica podría interpretar el desarrollo de la humanidad. Pero, si la interpretación es la apropiación violenta de un sistema de reglas, que en sí mismo no tiene un significado esencial, con la pretensión de imponer una dirección, que conforme una nueva voluntad, forzando su participación en un juego diferente, que a su vez se sujete a reglas secundarias, entonces el desarrollo de la humanidad es una serie de interpretaciones. El rol de la genealogía es archivar su historia: la historia de la moral, de los ideales, de los conceptos metafísicos, de la historia del concepto de libertad o de la vida ascética. En la medida en que tales narrativas significan el surgimiento de diferentes interpretaciones, deben de aparecer como acontecimientos en el escenario del proceso histórico.» "Nietzsche, genealogía e historia», en La microfisica del poder, Madrid, 1980, 18. A los mismos resultados llega R. RORTY en Contingencia, ironia y solidaridad, Barcelona, 1991, 40, 79-80. 
importante de estas interpretaciones proviene de Aristóteles, que considera que "la hembra es hembra en virtud de una falta de cualidades [siempre en relación al plenamente dotado varón]... debemos [a su juicio] mirar a la naturaleza femenina como infradotada»; de Santo Tomás, para quien la mujer es un «hombre imperfecto», un ser «incidental», o del propio Génesis, que presenta a Eva como hecha de lo que Bossuet llama «un hueso supernumerario» de Adán ${ }^{68}$. Si apelamos a la utoridad del Génesis, vemos que la tentación de Eva y la Caída de ambos (ella y Adán) tiene para Eva como consecuencia el castigo de Dios - dolor en el nacimiento y obediencia a la voluntad de su marido-. La mujer cristiana fue obligada a someterse a su marido así como se somete a Dios.

Desde el tiempo de los griegos se ha presentado a la mujer como el objeto bello de contemplación, su órgano sexual representa el horror de nada a lo que mirar. Resulta evidente en la estatuaria griega que este "nada a lo que mirar» tiene que ser excluido, rechazado, de tal escena de representación. Los genitales de la mujer están simplemente ausentes, enmascarados, cosidos dentro de su «rajadura». A este órgano que no tiene nada que mostrar le falta una forma propia. Y si la mujer obtiene placer erótico de tal incompletud de forma, tal placer es negado por una civilización que privilegia el falomorfismo. El uno de la forma, del individuo, del órgano sexual masculino, suplanta al al menos dos (labios vaginales) que mantienen a la mujer en contacto consigo misma, pero sin ninguna posibilidad de distinguir si es un contacto consigo misma o con algo externo. Su órgano sexual, que, como vemos, según la representación estatuaria griega y posterior, no es un órgano, es contado como ninguno. La mujer tiene órganos sexuales más o menos en todos los sitios, la geografía de su placer se extiende por todo su cuerpo, frente a la uniformidad localizada del falo masculino ${ }^{69}$.

Para Simmel, el problema fundamental radica en la discrepancia radical existente entre la forma del ser femenino y la cultura objetiva en general. La dominación fundada en la prepotencia subjetiva siempre ha tratado de procurarse una base objetiva, es decir, de transformar el poder en derecho. La superioridad psicológica que procura la relación de dominación entre varones y mujeres a las manifestaciones masculinas comparece, asimismo, como superioridad lógica y ética en el seno de un esquema de representación y clasificación de la vida social. El ideal de la razón moral imparcial corresponde al ideal del ámbito público de la política que procede de la Ilustración y que consigue la universalización de una voluntad general que deja a la diferencia, a la particularidad y al cuerpo en el ámbito privado ${ }^{70}$ de la familia y de la sociedad civil, pero no

${ }_{68}$ Ver al respecto la, sin duda, interesante e innovadora reinterpretación de lo femenino que introduce Simone DE BEAUVOIR en El segundo sexo, publicada en 1950.

${ }^{69}$ Ver L. IrigaraY, "The Sex Which Is Not One», en Gender, C. C. Gould (ed.), Athlantic Highlands, NJ, 1997, 120-127.

${ }_{70}$ Ver I. M. YounG, «The Idea of Imparciality and Civic Public», en Gender, op. cit., 360, 365. 
debemos olvidar que lo privado, como apunta Hanna Arendt ${ }^{71}$, está etimológicamente relacionado con la privación. Lo privado, como tradicionalmente se ha considerado, es lo que debiera ser ocultado a la vista o lo que no debe ser puesto a la vista. Está conectado con la vergüenza y con la incompletud. Esta noción de lo privado implica la exclusión de los aspectos corporales y afectivos de la esfera pública.

Este problema ha sido retomado, a través de una gran variedad de enfoques y planteamientos, por el feminismo actual. Seyla Benhabib realiza una crítica de las posiciones sobre el contrato social que van de Hobbes a Rawls, en lo relativo a la definición del ámbito moral así como en la autonomía moral ${ }^{72}$, afirmando que tales posiciones conducen a una privatización de la experiencia de la mujer y a una exclusión de su punto de vista en el ámbito moral. En esta tradición, el ser moral es visto como un ser desmembrado y desencarnado. En esta concepción el "otro relevante» nunca es la hermana, sino el hermano. Benhabib califica al enfoque citado de sustitutivo porque identifica la experiencia de un grupo específico, blancos, hombres y adultos, con el caso paradigmático de lo humano en cuento tal. La historia del contrato social es tratada como algo relacionado con la esfera pública de la libertad cívica, mientras el «contrato sexual» es desplazado al ámbito privado del contrato matrimonial. El pacto original es tanto un contrato sexual como social en el que se establece la libertad del hombre y la dependencia de la mujer. Tal contrato es sexual porque es masculino, al establecer el derecho político masculino sobre la mujer, y también es sexual porque establece el acceso ordenado del hombre al cuerpo de las mujeres $^{73}$. En la crítica de Benhabib se dibujan dos concepciones de relaciones sí mismo-otro que delimitan perspectivas morales y estructuras interaccionales diferenciadas. La primera de ellas es la del «otro generalizado» ${ }^{74}$ y la segunda es la del "otro concreto». El punto de vista del «otro generalizado» ve a cada individuo como un ser racional investido con los mismos derechos que desearíamos adscribirnos a nosotros mismos. Asumimos que el otro, como nosotros, es un ser que tiene necesidades, deseos y afectos concretos, pero lo que constituye su dignidad moral no es aquello que nos diferencia a unos de otros, sino más bien lo

${ }^{71}$ Ver H. AREndt, The Human Condition, Chicago, 1958, 58-67.

72 Ver S. BenhabiB, «The Generalized Other and the Concrete Other», originalmente publicado en Praxis International, vol. 5, núm. 4, 1986, 402-425, y recogido en Gender, C. C. Gould (ed.), Athlantic Highlands, NJ, 1997, 290 ss.

73 Ver C. Pateman, «The Sexual Contract», en Gender, op. cit., 317-324.

${ }^{74}$ A pesar de que el término de "otro generalizado" procede de G. H. Mead, la definición de Benhabib difiere de la de aquél. Para Mead, el «otro generalizado es la comunidad organizada o el grupo social que da al individuo su unidad de sí mismo. La actitud del otro generalizado es la actitud de la comunidad global» (G. H. MEAD, Mind, Self and Society, Chicago, 1955, 154). Entre tales comunidades, Mead incluye un equipo de beisbol, así como un club político, una corporación y otras clases sociales o subgrupos más abstractos, tales como la clase de los deudores y la de los acreedores (ibidem, 157). Ni siquiera Mead restringe el uso del "otro generalizado» a lo que se describe en el texto. De hecho, Mead critica la mencionada tradición del contrato social por la distorsión de la génesis psicosocial del sujeto individual que conlleva (ibidem, 233). 
que, como agentes racionales que hablan y actúan, tenemos en común. Nuestra relación con el otro, según este enfoque, está gobernada por normas de igualdad formal y de reciprocidad. Los sentimientos morales son aquellos de respeto, deber y dignidad. El punto de vista del "otro concreto" ${ }^{75}$ ve a cada ser racional como un individuo con una historia concreta, con una identidad y con una constitución afectivo-emocional. En este planteamiento buscamos comprender las necesidades del otro, sus motivaciones, y lo que desea. Nuestra relación con el otro está gobernada por normas de equidad y de complementariedad reciproca. Nuestras diferencias en este caso complementan más que excluyen al otro. Las normas de nuestra interacción son normalmente privadas, no institucionales; son normas de amistad, amor y cuidado. Las categorías morales que acompañan a estas interacciones son la responsabilidad, el vínculo, el compartir, y los sentimientos morales correspondientes son los de amor, cuidado, simpatía y solidaridad. Tratándote con arreglo a estas normas, yo confirmo no sólo tu humanidad, sino tu individualidad humana (en nuestro caso femenina, de mujer). "La construcción femenina del problema moral como un problema de cuidado y responsabilidad en las relaciones, más que un problema de derechos y reglas, vincula el desarrollo de su pensamiento moral a los cambios en su comprensión de la responsabilidad y de las relaciones, así como la concepción de la moralidad y de la justicia (abstracta) vincula el desarrollo a la lógica de la igualdad y de la reciprocidad. Así la lógica que subyace a una ética del cuidado es una lógica psicológica de las relaciones que contrasta con la lógica formal de la equidad que informa el enfoque de la justicia» ${ }^{76}$. El ser autónomo es alguien nacido de otros, concretamente de otra, y no, como Rawls, siguiendo a Hobbes, asume, un ser «no vinculado a otro por vínculos morales previos» ${ }^{77}$. Como ha puesto de manifiesto Nancy Chodorow, «la comprensión por parte del hombre y de la mujer, de la diferencia y de la diferencia de género, debe ser entendida en el contexto relacional en el que éstas son creadas. Estas diferencias surgen de la relación respectiva de los niños y de las niñas con su madre, que es ese primer otro que los cuida, su objeto de amor, y objeto de identificación ${ }^{78}$. El ser no es una cosa, un sustrato, sino el protagonista de un cuento sobre la vida. La concepción del ser como individuado, previamente a sus fines morales, es incoherente. Si esto fuera así, no podríamos conocer si tal ser es un ser humano, un ángel o el Espíritu Santo ${ }^{79}$.

75 Para construir el contraconcepto de «otro concreto", Benhabib se apoya en las extraordinarias investigaciones de Nancy CHODOROw, The Reproduction of Mothering: Psychoanalysis and the Sociology of Gender, Berkeley, 1978, y de Carol Gilligan, In a Different Voice. Psychological Theory and Women's Development, Cambridge, Mass., 1982.

${ }^{76}$ C. Gilligan, In a Different Voice, 73.

77 J. RaWls, A Theory of Justice, Cambridge, Mass., 1971, 137.

78 N. Chodorow, "Gender, Relation and Difference in Psychoanalitic Perspective», en Gender, op. cit., 37.

79 Dada esta distinción entre una ética abstracta y putativamente masculina de la justicia formal que se basa en principios generales y una ética contextual putativamente femenina de la justicia sustantiva basada en la co(m)pasión y el cuidado, la primera estaría representada por el 
En el tiempo de Simmel coexisten tres modelos interpretativos básicos de relación entre la mujer y la cultura:

a) El modelo de esferas separadas. En respuesta a los movimientos feministas de mediados del siglo XIX, la exclusión de la mujer de los derechos y estatuses del Estado liberal que estaban abiertos al hombre fue elevada a principio y elaborada como una ideología que explicó y legitimó la posición de que hombres y mujeres ocupan esferas de la vida distintas, mutuamente excluyentes y no intercambiables. Brevemente se puede resumir esto en cuatro aspectos:

- La dicotomía mercado/hogar. Este modelo reserva todo lo no doméstico, la producción económica, al hombre. Idealmente, la mujer fue incluso exonerada de toda la producción doméstica, con excepción del cuidado de la prole y la vigilancia de los asuntos domésticos.

- La dicotomía público/privado. Esto significa que el hombre y la mujer, miembros de la familia, están separados durante el trabajo. Los hombres van a los centros de trabajo y de actividad cívica, los niños/as van a la escuela y las mujeres permanecen en casa.

- La dicotomía producción/consumo. El hogar, el lugar de la mujer, era el locus del consumo. Esta especialización de la mujer surge como consecuencia de la separación entre economía doméstica y la empresa, apuntada por Max Weber.

- El dualismo ético. Este modelo impuso una ética de la caridad, de la castidad y del sacrificio a la mujer frente a los valores del logro y el heroísmo afincados en la cultura masculina.

Este modelo confina la participación de la mujer en la cultura objetiva al ámbito del hogar. El hogar es «el logro cultural supremo de la mujer» porque es el único logro cultural de la mujer, la única forma cultural a la que ha dado expresión la existencia femenina sin fragmentarse y sin destruir su homogeneidad. Esto es así porque las propiedades del hogar reproducen las cualidades básicas de la vida de la mujer en el ámbito de la cultura objetiva ${ }^{80}$.

b) El modelo liberal. En Alemania, la fuente principal para el modelo liberal fue el famoso artículo de John Stuart Mill «On the Subjection of Woman», de 1869, que fue ampliamente leído y tuvo gran influencia. Según

capitán Vere en Billy Budd, Saylor, de Herman Melville, mientras que la segunda estaría representada por Porcia, la rica heredera de El Mercader de Venecia, de William Shakespeare.

${ }^{80}$ Esta concepción de la simetría entre el hogar y la existencia de la mujer es, por supuesto, una tesis altamente cuestionable. Considérese, por ejemplo, el viejo protofeminismo implícito en las tragedias domésticas, de la alta burguesía, de Ibsen. En La casa de muñecas, Hedda Gabler, El maestro constructor, Rosmersholm, el hogar es una prisión moral y psicológica o una clínica de prácticas de psicopatología. O considérese, asimismo, el nuevo feminismo contemporáneo afincado en las clases medias, que representa al hogar como un locus de despolitización y de privatización de la mujer. 
Mill, los principios que gobiernan el acceso a la cultura objetiva por parte de los hombres, es decir, la libertad como capacidad de elección ${ }^{81}$, deberían extenderse a las mujeres asimismo; en otras palabras, las mujeres merecen aquello que los hombres ya tienen.

c) El modelo socialista. El tercer modelo básico de relación entre la mujer y la cultura que influye en la época de Simmel es el del feminismo socialista. Este modelo suscribe el ideal básico del liberalismo y su solución al problema del feminismo: acceso igual de las mujeres a las formas de la cultura. Sin embargo, se diferencia de aquél en tres aspectos: 1) El feminismo socialista niega a la mujer el derecho liberal a la propiedad privada, así como a otros derechos dependientes de éste. 2) El modelo socialista mantiene que la mujer no puede alcanzar el acceso a tales formas de la cultura dentro de los límites del Estado liberal, debido, por un parte, a la cualidad patriarcal de tal orden liberal y, por otra parte, debido a su cualidad explotadora. 3) Si esto es así, la genuina emancipación femenina sólo será posible por la transformación revolucionaria de tal orden ${ }^{82}$.

Todos estos modelos son, a juicio de Simmel, reduccionistas porque no reconocen la autonomía de lo femenino como una forma de vida que estructura la experiencia humana. El modelo de las esferas separadas subordina la femineidad a la maternidad y a la familia y, en el caso de la Alemania guillermina, al interés nacional de la patria inclusive. Los modelos liberal y socialista son reduccionistas por cuanto derivan los ideales y valores feministas de los presupuestos políticos básicos del liberalismo y del socialismo. Desde la perspectiva de cada modelo, ser una mujer representa un estatus contingente o derivado que depende de alguna otra condición. Ésta es la razón fundamental por la que Simmel no puede aceptar estos modelos. En su perspectiva, la experiencia humana está definida y moldeada por una pluralidad de formas de vida que son independientes unas de otras. Ser una mujer es una de estas formas. Su enfoque antirreduccionista representa: una crítica de la teoría de la racionalidad de la Ilustración, como un conjunto de leyes teóricas y prácticas de la razón que se aplican a toda la experiencia de la misma manera; una ontología de la experiencia humana que está comprometida con la perspectiva de que la vida humana no puede ser reducida a una única forma; una epistemología que se apoya en una pluralidad de modos radicalmente diferentes e inconmensurables de conocimiento; y una concepción de la modernidad que mantiene que la variedad de formas de vida está amenazada por la progresiva "mediatización» de la experiencia humana en la economía monetaria.

${ }^{81}$ Ver al respecto los interesantes estudios de A. S. Rossi (comp.), Ensayos sobre la Igualdad sexual. Joh Stuart Mill y Harriet Taylor Mill, Barcelona, 1973, Introducción, y de N. CAMPILlo, «J. St. Mill: Igualdad, criterio de la modernidad», en M. a A. Durán (ed.), Mujeres y hombres en la formación de la teoría sociológica, Madrid, 1996, 73-111.

${ }^{82}$ Ver la colaboración de M. F. ENGUiTA, «El marxismo y las relaciones de género», en M. ${ }^{a}$ A. Durán (ed.), op. cit., 37-58. 
Simmel, a diferencia de estos modelos ya existentes, va a partir del supuesto de que existen dos constelaciones de género claramente diferenciadas, cuyas características más importantes recoge a lo largo de los dos artículos ya cita$\operatorname{dos}^{83}$ : "Cultura femenina» (1911) y «Lo relativo y lo absoluto en el problema de los géneros» (1911):

\begin{tabular}{l} 
Constelación femenina \\
\hline Lo sombrío \\
Agua \\
Luna \\
Interior \\
El sur caliente \\
Húmedo \\
Latente \\
Contracción \\
Reacción \\
Concavidad \\
Completitud \\
Respuesta \\
Recepción \\
Ser \\
El color negro \\
La serpiente, el dragón \\
Cuidado y afecto \\
Uniformidad \\
Integración \\
Personalización \\
Mediación
\end{tabular}

\section{Constelación masculina}

Lo claro

Fuego

Sol

Exterior

El norte frío

Seco

Manifiesto

Expansión

Estimulación

Convexidad

Comienzo

Movimiento

Inicio, emisión

Hacer

El color rojo

El águila, el león

Justicia abstracta

Especialización

Distanciamiento

Despersonalización

Inmediatez

El hombre separa su personalidad global de la correspondiente relación particular y experimenta ésta en la objetividad pura; la mujer, por el contrario, no puede representarse esta relación momentánea como una relación impersonal, sino que la experimenta inseparablemente de su ser global y unitario. Los hombres consideran a menudo a la mujer como «cosa» (objeto); sin embargo, ésta no puede proceder de la misma forma con el hombre. La mujer vive en la identidad más profunda de su ser y de su condición de mujer, en el carácter absoluto de una condición sexual determinada en sí misma ${ }^{84}$, que no precisa

${ }^{83}$ Ver el análisis de J. M. DE Miguel sobre el concepto de subcultura femenina en Simmel intitulado "Georg Simmel: La construcción social del género femenino como subcultura», en M. a A. Durán (ed.), op. cit., 59 ss.

${ }^{84}$ Ver G. Simmel, Filosofía del dinero, op. cit., 468 ss. 
para ser sustancial de la relación con el otro sexo. El varón es un ente determinado (entiéndase socialmente determinado), para la división del trabajo y por la división del trabajo, es decir, por una específica forma de objetivación histórica. Así proyecta una actitud de dominio, de control, de intervención en el mundo, que se ha puesto de manifiesto en la historia de la política, del sacerdocio, de las formas económicas, del derecho familiar, etc. El varón crea lo objetivo, sale de sí mismo, se objetiva; por tanto, se hace objeto para sí mismo y para los demás, sólo él es capaz de desensimismarse; sin embargo, la condición de la mujer permanece en sí misma, su mundo gravita en su propio centro. Ella es el auténtico "ser humano", frente al varón, que es "mitad bestia, mitad ángel», «mitad Jekill, mitad Hyde»; una mitad deviene la otra mitad por su propia naturaleza afín a la diferenciación. El ser del hombre, dualista, inquieto, entregado a la indeterminación del devenir, exige su redención en un hacer objetivado. Toda la inversión de la secuencia teleológica medios-fines, mencionada arriba como autonomización no deseada de la cultura objetiva realmente existente, tan profundamente enraizada en la esencia masculina, es inaplicable con la misma profundidad a la femenina. El varón es capaz de vivir y morir por una idea, pero esa idea se sitúa siempre indefectiblemente fuera de él, es su tarea infinita; él es siempre, en sentido ideal, un solitario. Pero, para la mujer, su ser y la idea son una misma cosa; la mujer, aunque en ocasiones se vea reducida por el destino, socialmente producido por el hombre, al aislamiento del hogar, nunca es tan típicamente solitaria como lo es el hombre; ella siempre está consigo misma en su casa, mientras que el hombre busca siempre su "casa» fuera de sí mismo ${ }^{85}$. Por un lado, se encuentra lo masculino como absoluto, que es más que masculino, que significa la objetividad, la elevación normativa por encima de toda subjetividad y antagonismo alcanzada al precio del dualismo (sujeto-objeto); por otro lado, está lo femenino como absoluto, que incorpora en su inmóvil reclusión sustancial la unidad del ser humano previa a la diferenciación entre sujeto y objeto ${ }^{86}$. Las mujeres dan la sensación de una cierta falta de desarrollo, de albergar capacidades que no han llegado a realizarse, al margen de todos los obstáculos a su desarrollo derivados de los prejuicios y los quebrantos sociales. Sin duda, no es correcto ver en esta «indiferenciación» tan sólo una insuficiencia, un atraso. Más bien, es ésta la forma, absolutamente positiva, en que se expresa la esencia de la mujer, constituyendo un ideal en sí misma, y situándose con iguales credenciales al lado de la "diferenciación» del hombre. Sin embargo, contemplada desde la óptica del hombre, esta característica propia de la mujer aparece como un "todavía no", como una posibilidad incumplida ${ }^{87}$. Mientras algunas feministas influyentes, historiadores del arte y críticos se han fijado en la mujer como un objeto de la mira-

${ }^{85}$ Ver G. SIMMEL, «Das Relative und das Absolute im Geschlechter-Problem», en SPSG, 211 (Cultura femenina..., 93).

${ }^{86}$ Ver G. Simmel, «Das Relative...», op. cit., 223 (Cultura femenina..., 114).

${ }^{87}$ Ver G. SimmeL, «Psychologie der Koketterie», en SPSG, 195 (Cultura femenina..., 133). 
da masculina en las pinturas victorianas, Stephen $\operatorname{Kern}^{88}$ argumenta que si bien la mirada masculina en las pinturas está más orientada eróticamente, la mirada femenina expresa una mayor tensión entre el deseo sexual y el amor, considerando al último como un anhelo de unión moral recíproca y duradera entre dos personas. La mirada femenina es menos servil a la expresión masculina de deseo sexual o de placer de lo que a menudo se sugiere en la historia del arte, reflejando un conocimiento más maduro de la realidad mundana que refleja la tensión entre la esperanza y la experiencia.

\section{EL GÉNERO IN-CORPORADO, EL CUERPO GENERIZADO, COMO EL OBJETO DE UNA FENOMENOLOGÍA DE LA MATRIZ CULTURAL FEMENINA}

El sistema sexo-género es una manera esencial de organización de la realidad social, de división simbólica, que se vive a través de la propia experiencia. Representa la constitución sociohistórica y simbólica, así como la interpretación, de la diferencia de género. El marco primario constituido por el cuerpo con sus dos posibilidades, portador de pene y portador de vagina, sólo es socialmente viable a través de la experiencia personal de un marco secundario que sirve para organizar tal experiencia con arreglo a unas claves interpretativas o a unas constelaciones de sentido, femenina y masculina, en los términos esbozados por Simmel arriba, que constituyen lo que llamamos género ${ }^{89}$. El sistema género-sexo es aquella rejilla a través de la cual el «sí mismo» desarrolla una identidad in-corporada, un cierto modo de ser en un cuerpo. Sólo podemos hablar de «sí mismo" personal, de identidad, en cuanto que existe un modo de experimentar psíquicamente, socialmente y simbólicamente tal pre-identidad corporal, modo para el que nos servimos de los patrones/matrices de la comunidad humana ${ }^{90}$. Pero vamos a ver con un poco más detenimiento cómo se produce tal «organización significativa de la experiencia» que lleva a la constitución del ser masculino o femenino.

En orden a realizar esta identificación simbólica, cada uno debe renunciar a su bisexualidad psicológica naturalmente posible, cuya existencia en las personas modernas se muestra, entre otras cosas, en que el lado femenino del hombre comparece como anima ${ }^{91}$ y el lado masculino de la mujer comparece

${ }^{88}$ Ver S. Kern, Eyes of Love: The Gaze in English and French Paintings and Novels, 18401900, Londres, 1996.

89 Sobre el concepto de «marco» para la organización de la experiencia, ver E. Goffman, Frame Analysis, Notre Dame, Indiana, 1973, sobre todo la Introducción.

${ }^{90}$ Erwing GofFman también hace una interesante crítica de la posición biologicista, basada en el dimorfismo corporal — pene-vagina-, en "The Arrangement betwen the sexes», en Theory and Society, vol. 4, núm. 3, 1977, 301-331.

${ }_{91}$ El anima representa la personificación femenina del inconsciente masculino, es decir, representa la mujer interior que inhabita en el hombre. 
como animus ${ }^{92}$, es decir, en ambos casos se produce un proceso de sublimación que conlleva una realización imaginal de un aspecto (anima y animus) y una realización objetiva de la constelación dominante (mujer, varón). La identificación del hombre con la estructura de la conciencia y del yo, abandonando su lado femenino inconsciente, facilita psicológicamente este proceso de unilateralización. La conexión del hombre con la mujer está ahora determinada de una manera característica: su conciencia puramente masculina se relaciona con la femineidad de la mujer, sobre la que proyecta su propia femineidad inconsciente en la forma de anima. De la misma forma, la mujer conscientemente se relaciona como puramente femenina con la masculinidad del hombre y proyecta sobre él su propio lado inconsciente masculino en la forma de animus. El hecho de que esta división de roles aparezca en todas las narrativas sobre la construcción del sujeto significa que el canon cultural masculino (o patriarcal), según el cual son criados cada muchacho y cada muchacha, otorga una posición central y un honor especial a este rango limitado de posibles tipos de relación ${ }^{93}$. Esto significa que el hombre «femenino» y la mujer «masculina» — contrariamente a la estructura psíquica actual de una multitud de individuosson ahora considerados como formas repulsivas de la existencia humana y son suprimidas desde el principio. El resultado de esto es una polarización de lo masculino y lo femenino, del varón y de la mujer, que parecen crear una situación inequívocamente objetiva. Esta erradicación de la ambivalencia ${ }^{94}$ conduce al sentimiento de seguridad relacionado con la orientación de la conciencia dentro de una cultura objetiva masculina (patriarcal) en la que Masculino= varón y Femenino=mujer, y que demanda como su esquema clasificatorio ideal que la mujer y el hombre se identifiquen a sí mismos en los términos de este esquema inequívoco. Ésta es la estructura simbiótica que conforma las bases de la familia y de la cultura masculina patriarcal, que garantiza no sólo la seguridad y lo inequívoco del esquema, sino también la tensión inherentemente fértil de opuestos entre lo masculino y lo femenino, entre hombre y mujer, que caracterizan a la relación heterosexual como relación «normal» entre génerosexos. La mujer nunca siente que ella es "sí misma» cuando identifica su yo con las estructuras de conciencia dominantes de la cultura objetiva. A menudo parece que la mujer está alienada de sí misma debido a que experimenta una tensión entre la estructura objetiva simbólicamente masculina y la estructura de su propia constelación femenina como totalidad. Mientras que para la

92 El animus representa la personificación masculina del inconsciente femenino, es decir, representa el hombre interior que inhabita en la mujer.

${ }_{93}$ Ver E. Neuman, «Stages of Woman's Development», en The Fear of the Femenine, Princeton, NJ, 1994, 31 ss.

${ }_{94}$ Es importante hacer notar que la presencia de la ambivalencia (como fuerza motriz, como la negación de los opuestos y como la afirmación de la posibilidad de ser ambos) es lo que caracteriza a la creatividad específicamente humana. Así lo documenta E. NeumanN en su texto Creative Man, Princeton, NJ, 1979, donde dedica varios ensayos a las personalidades creativas de Kafka, Trakl, Chagal, Freud, Jung y Dalí. 
mujer son requeridas tanto la femineidad (propia) y la masculinidad (social), para el hombre es requerida únicamente la masculinidad, en la que coincide lo individual y lo social.

Pero no perdamos de vista el sendero de interpretación sociológica inaugurado por Simmel, en especial su énfasis en la construcción social asimétrica de las dos constelaciones de género. Hablamos de construcción y de experiencia cuando hablamos del género, y lo hacemos en la convicción de que no es algo dado, ningún sujeto es su propio punto de partida. El sujeto está situado, el sujeto, este sujeto, yo estoy constituido por determinadas posiciones, según las cuales me posiciono, y estas posiciones no son meramente productos teóricos, sino principios organizadores, clasificadores, de prácticas materiales y de tareas institucionales, cuyas matrices de poder y discurso me producen como un «sujeto" viable $^{95}$. El sujeto comparece socialmente como sujeto generizado, como sujeto que in-corpora y expresa alguna de las constelaciones de género reseñadas, y este género, el mío, el tuyo, el suyo, es «una clase de imitación para la cual no existe original ${ }^{{ }^{66}}$, es un tipo de imitación que produce la noción de original como un efecto y consecuencia de la imitación misma. Los efectos naturalizadores del género heterosexual son producidos a través de estrategias imitativas. Lo que ellas imitan es un ideal fantasmático de identidad heterosexual, que es producido por la imitación como efecto suyo. En este sentido, la "realidad» de las identidades heterosexuales está performativamente constituida a través de una imitación que se sitúa a sí misma como el origen y el fundamento de todas las imitaciones. La posibilidad de llegar a ser un sujeto viable requiere el acto performativo de imitación de un cierto género. Este género no es un acto performativo que un Sujeto previo decide realizar, sino que es performativo en el sentido de que se constituye a sí mismo como un efecto de lo que expresa el sujeto en cuestión ${ }^{97}$, como un correlato de su decisión propia, o de la decisión de otros que deciden por él (las respectivas agencias de socialización, familia, escuela, iglesia). El género es siempre un hacer. No existe identidad de género antes de las expresiones del género, la identidad es performativamente constituida por tales «expresiones» que proclaman ser sus resultados ${ }^{98}$. El sujeto está internamente constitutido por Otros generizados diferencialmente; por lo tanto, nunca es un sujeto autoidéntico. El sujeto sólo puede constituirse como tal sujeto si experimenta, sería más correcto decir, si sufre una separación, una pérdida de la primera alteridad con la que tenemos contacto, la madre, que se supera por la incorporación melancólica provisional o definitiva de algún «Otro» masculino o femenino, de algún modelo de referencia.

95 Ver al respecto la interesante reflexión de J. BuTLER en "Contingent Foundations», recogido en J. Butler y J. W. Scott (eds.), Feminist Theorize the Political, Londres, 1992, 9.

96 J. ButLer, «Imitation and Gender Insubordination», incluido en Ch. LEMmerT, Social Theory, Boulder, Colorado, 1993, 643 ss.

${ }_{97}$ J. BUTLER, op. cit., 645.

98 J. ButLer, Gender Trouble. Feminism and the Subversion of Identity, Nueva York, 1990, 25-26. 
Consideremos el siguiente ejemplo: cuando la cantante de blues Aretha Franklin canta "you make me feel like a natural woman", ella parece sugerir en principio que algún potencial natural de su sexo biológico es actualizado por su participación en la posición cultural de «mujer» como objeto de reconocimiento heterosexual. Algo en su "sexo" es expresado por su "género", que es completamente conocido y consagrado dentro de la escena heterosexual. Sin poner en duda en ningún momento la naturalidad aparente de la actuación, es decir, la adecuación entre sexo y género desde una perspectiva heterosexual, ella es completamente consciente de que tal confirmación nunca está garantizada, de que el efecto de naturalidad es conseguido sólo como consecuencia de tal momento de reconocimiento heterosexual. Después de todo, Aretha canta "you make me feel like a natural woman", sugiriendo que esto es un tipo de sustitución metafórica, una clase de participación sublime y momentánea en una «ilusión» ontológica, socialmente creada y recreada. La psique generizada no es algo que está «en» el cuerpo, sino que es algo que emerge en el proceso de significación a través del cual ese cuerpo aparece. Las categorías de sexo, de identidad sexual, de género, son producidas o mantenidas en los efectos de su performatividad compulsiva, efectos que sin ninguna ingenuidad son llamados causas, orígenes, y que sin ninguna ingenuidad son alineados dentro de una secuencia expresiva o causal que la norma heterosexual produce para legitimarse a sí misma como el origen de todos los sexos.

Simmel presenta una serie de actos performativos a través de los cuales se configura una fenomenología inmanente en la que comparecen una serie de actuaciones como la prostitución, la coquetería, la moda y la aventura (como una extrañeza, una alteridad, un estar-al-margen de lo normal y cotidiano), a través de las que el género se in-corpora y el cuerpo se generiza, conformando de esta guisa una matriz cultural femenina con sus propios principios de organización de la experiencia dentro de la cultura objetiva.

Veíamos más arriba que el dinero está completamente separado de la persona que lo usa; al pagar con dinero, el hombre termina definitivamente con un asunto, tan definitivamente como con una prostituta, después de la satisfacción erótica obtenida. El dinero no es jamás mediador adecuado para una relación entre los seres humanos que, por razón de su esencia, precisa de la duración y la sinceridad interna de las fuerzas vinculantes, como ocurre en el caso de la relación amorosa auténtica, por muy rápido que se rompa. El dinero, en cambio, proporciona el servicio más perfecto, objetiva y simbólicamente en el caso del placer comprado, que rechaza toda relación que trasciende el momento y el impulso puramente sensorial, puesto que, al ser comprado, se separa por completo de la personalidad e ignora cualquier consecuencia posterior. En la esencia del dinero se experimenta algo de la esencia de la prostitución. No andaba desencaminado Marx cuando, recogiendo una expresión de Carlyle, llama al dinero «la ramera universal». La indiferencia con que éste se presta a todo tipo de empleo, la infidelidad con que se separa de cada sujeto (porque no está vinculado a ninguno), la objetividad que excluye toda relación 
íntima y que le da su carácter de puro medio, todo esto justifica una analogía adecuada entre el dinero y la prostitución. Frente al mandato moral de Kant de que nunca hay que utilizar a un ser humano como mero medio, sino reconocerle en todo momento como fin, la prostitución muestra el comportamiento absolutamente opuesto que afecta a las dos partes que intervienen. De entre todas las relaciones mutuas de los seres humanos, la prostitución es el caso más patente de una degradación recíproca al carácter de puro medio. «Aquí experimentamos la desproporción más completa y más penosa entre la prestación (sexual) y la contraprestación (económica), o, más bien, y ésta es, precisamente, la degradación de la prostitución, que rebaja de tal manera la propiedad personal y más reservada de la mujer, que el valor más neutral de todos, el más alejado de todo lo personal, se considera como un equivalente de aquél $»^{99}$. En la prostitución, la mujer experimenta el mayor grado de alienación, es decir, de objetivación distorsionada, puesto que de ser un fin en sí misma deviene medio; mientras que la sociedad degrada insalvablemente a la prostituta, el peor de los libertinos siempre puede salir del cenagal por medio de otras facetas de su personalidad y recuperar su perdida posicición social, por la razón de que el varón se divide, se diferencia, no se entrega con todo su ser, mientras que la mujer ofrece toda su persona. La intervención de la mujer es infinitamente más personal, más esencial, más comprensiva del yo que la del hombre, y el equivalente monetario de ella es lo más inapropiado y lo más desproporcionado que se pueda imaginar, cuya ofrenda y recepción implica la degradación más profunda de la personalidad de la mujer.

En la coquetería, algo primordialmente femenino, la pretensión es despertar el agrado y el deseo por medio de una antítesis y síntesis singulares, ofreciéndose y negándose alternativa o simultáneamente, diciendo un sí y un no simbólico, meramente indicado, "como desde lejos", por medio del dar y el no dar o, hablando en términos platónicos, contraponiendo la posesión y la no posesión, aunque dando la impresión de que ofrece ambas de una sola vez ${ }^{100}$, es decir, jugando con la ambivalencia. La coqueta "quiere agradar", pero no quiere ser poseída inmediatamente, sino con arreglo a un juego ritual, en el que se pone un "precio» que implica sacrificios y esfuerzo; no es algo que permite satisfacer el deseo, sino sólo de manera diferida; esto transforma a la mujer propiamente en atractiva y deseable. Tiene el aliciente de lo secreto, de lo furtivo, de lo que no puede ser duradero, sirviéndose de la mirada de reojo, con la cabeza ladeada, mezclándose en ella de forma inseparable el sí y el no. La coquetería es en grado sumo lo que Kant ha dicho de la esencia del arte: "finalidad privada de fin»" ${ }^{101}$. La coqueta se conduce como si sólo se interesara por su pareja de cada momento, pero, sin embargo, deja flotar de manera

99 G. Simmel, Filosofía del dinero, op. cit., 467.

100 Ver G. Simmel, "Psychologie der Koketterie», en SPSG, op. cit., 189 (Cultura femenina..., op. cit., 116).

${ }_{101}$ Ver G. Simmel, op. cit., 194 (Cultura femenina..., op. cit., 129). 
inconsecuente en el aire sus actos, dándoles una finalidad por completo distinta: agradar, subyugar, ser deseada, pero sin permitir que se la tome en serio cuando procede así. La coqueta se conduce guiada por una «finalidad», pero rechazando el «fin» al que debería llevar su conducta en el orden de la realidad y encerrándolo en el placer puramente subjetivo del juego. La coquetería se divide en la dedicación a un objeto alternando con la dedicación a todo lo contrario. El uso de determinados vestidos, generalmente más llamativos en la mujer, y la ocultación de determinadas partes del cuerpo femenino, ponen de manifiesto la indudable intención de llamar la atención hacia esas partes. A juicio de Simmel, esta ocultación en su origen es sólo adorno, con la doble función de todo adorno, que consiste, por un lado, en atraer las miradas hacia el objeto adornado, ganando para él una mayor atención, y, por otro, en hacer aparecer ese objeto como valioso y atractivo, merecedor de la atención preferente que se le dedica. Pero no olvidemos que tal adorno sólo puede cumplir su función si al mismo tiempo oculta lo adornado o lo deja ver de forma parcial, recurriendo al escote, a la falda más o menos corta, al corpiño, al sujetador, al pantalón ajustado, a la blusa ceñida, que definen la curvilinealidad del cuerpo femenino. Lo que permite a la coqueta ser el sujeto de la acción, a diferencia de la prostituta, frente al varón, al que aquí no le queda más remedio que asumir la posición de objeto, no es sino su juego con el tiempo, al jugar con la posesión y la no posesión, no siendo ninguna de ellas, pero pudiendo ser ambas; no hay un paso de la posesión a la no posesión, sino un «ser» simbólicamente las dos cosas a un tiempo; la coqueta, dueña del sí y del no, proyecta el presente como futuro; en el momento en que abandone la ambivalencia dejará de definir la situación según «sus» reglas, dejará de ser sujeto y pasará a ser objeto. Lo que le confiere a la coqueta su poder es que es ella quien elige y, por tanto, ahora es el varón quien se siente inseguro e inerme. En ese jugar (pautado) a acercarse y alejarse, a coger para luego dejar, a abandonar para volver a tomar, en esta manera de proceder, ha encontrado el alma la forma adecuada para relacionarse con un sinnúmero de cosas y, con la formulación difícilmente superable del propio Simmel, si «un momento tan trágico de la vida puede revestir la forma juguetona, vacilante y que a nada compromete, que nosotros llamamos coquetear con las cosas, comprendemos que esta forma encuentra su realización más típica y más completa en la relación de los sexos, en la relación que envuelve la quizás más oscura y trágica unión de la vida en la forma de su máximo delirio y de su más brillante atractivo» ${ }^{102}$.

El hecho de que la moda exprese y haga énfasis a un tiempo en la tendencia a la igualación y la tendencia a la individualización, el gusto por imitar y el gusto por distinguirse, explica quizá por qué las mujeres son, en general, más intensamente proclives a seguirla. De la debilidad de la posición social a la que se han visto condenadas las mujeres la mayor parte de la historia se deriva su estrecha identificación con todo lo que son «buenas costumbres», con «lo que

${ }^{102}$ G. Simmel, op. cit., 198 (Cultura femenina..., op. cit., 138). 
debe hacerse», con el mundo instituido de significado. Sobre este terreno firme de la costumbre aceptada, de lo común y corriente, del nivel medio, procuran con fuerza conseguir las mujeres toda la individualización y la distinción de la personalidad que, aun relativa, sea posible ${ }^{103}$. Sólo es posible individuarse, «distinguirse», como mujer, sin ningún peligro, toda vez que se haga desde el mimetismo de la cultura objetiva masculina. La moda es el mejor instrumento que permite combinar ambos aspectos, mimetismo y distinción: por una parte, representa un mimetismo general de lo socialmente aceptado, descargándose de cualquier responsabilidad por sus gustos y actividades, puesto que la imitación libera al individuo de la aflicción de tener que elegir, y, por otra parte, introduce la posibilidad de destacar a través del ornato individual de su propia personalidad. La esencia de la moda radica en que siempre es sólo una parte del grupo quien la ejerce (surge en el seno de las clases acomodadas), mientras que el conjunto del grupo se limita a estar en camino hacia ella. Pero el hecho de que la moda contribuya a individuar a la mujer no debe ocultarnos su anclaje en la cultura objetiva moderna, en esa cultura basada, como vimos más arriba, en el cambio, en la puesta entre paréntesis de pasado y futuro, inscribiendo su impronta en el presente como "imperio de lo efímero» ${ }^{104}$, de lo caduco; "hallamos la contemplación (propia de las sociedades tradicionales) sustituida por la sensación, la simultaneidad, la inmediatez y el impacto» ${ }^{105}$, y la moda no se sustrae a esta caracterización, más bien la representa; de hecho, un objeto sólo sufre una desvalorización si se le califica de "cosa de moda». La moda es la "trascendencia» del nacimiento como nueva fuente de novedad, y "trasciende» la muerte haciendo de la mercancía inorgánica el objeto del deseo humano ${ }^{106}$. Con su poder para dirigir el deseo libidinal hacia la naturaleza inorgánica, la moda conecta el fetichismo de la mercancía, el fin que se hace medio, con el fetichismo sexual característico del erotismo moderno. Así como el maniquí tiene partes separables, la moda fomenta la fragmentación fetichista del cuerpo viviente de la mujer. Es quizás en el ámbito cinematográfico donde mejor se ha puesto esto de manifiesto, concretamente en el «troceamiento» erótico del cuerpo de la mujer considerado como objeto del deseo; así ocurre en la década de los años treinta con la pasión por el pecho de Mary Pickford, que deja paso en los cuarenta a las piernas de Joan Crawford, que, a su vez, son sustituidas en la década de los cincuenta por la centralidad cuasigenital del pubis angelical de Marylin Monroe, que finalmente se expansiona hacia la implosión de la totalidad del cuerpo como fetiche en el cine más reciente, teniendo como referencia más representativa a Brigitte Bardot, y en la fotografía artística, entre cuyos más cualificados representantes cabe citar a Robert Maplethorpe y su musa, Lisa Lyon, modelo de referencia de este cuarto «troceamiento» del cuerpo femenino.

${ }^{103}$ Ver G. Simmel, «La Moda», en Cultura femenina..., op. cit., 53-54.

104 Gilles LIPOVETSKY es quien con mayor acierto ha radicalizado esta tesis de Simmel en L'empire de l'éphémere, La mode et son destin dans la société modernes, París, 1987.

105 D. BELL, Las contradicciones culturales del capitalismo, Madrid, 1977, 109.

106 Ver W. Benjamin, Das Passagen-Werk, op. cit., vol. 1, 130. 
Finalmente, la aventura ${ }^{107}$ representa, a juicio de Simmel, el mejor ejemplo de ese individuo que vive el presente, independiente del antes y del después. El estar al margen del tiempo, propio de la aventura, asumido por quien percibe en el conjunto de la vida real el latido de una secreta e intemporal existencia del alma, percibirá también la vida como una aventura. Cuando se entiende que en la tierra hallamos sólo un hospedaje fugaz y no un hogar, nos encontramos, evidentemente, ante un matiz peculiar del sentimiento general de que la vida en su conjunto es una aventura. El escepticismo del espíritu aventurero, que "no cree en nada", aquel para quien lo improbable deviene probable y, correlativamente, para quien lo probable será altamente improbable, tiene una gran afinidad con el umbral de contingencia y de cambio de las sociedades modernas.

\section{EL AMOR: CLÁSICO Y MODERNO}

El amor pertenece a las grandes categorías configuradoras de lo existente, es un universal cultural que conlleva una sobrecarga de significación. Aunque el amor de pareja sea su expresión más habitual, no se reduce a ella; los objetos amorosos son muy variados: amor fraternal, amor materno, amor erótico, amor a sí mismo, amor a Dios, amor entre padres e hijos ${ }^{108}$. Como afirma Octavio Paz ${ }^{109}$, el amor va más allá del cuerpo deseado y busca el alma en el cuerpo y el cuerpo en el alma. Stricto sensu, si puedo decirle a alguien «te amo", debo poder decir "amo a todos en ti, a través de ti amo al mundo, en ti me amo también a mí mismo»" ${ }^{110}$. Para Simmel, el amor es el lado de una relación-conexión existente en el sujeto, en la que está implicado todo su ser y cuyo otro lado está fuera de é $l^{111}$. En la propia tradición judeo-cristiana, después de que hombre y mujer se hicieron conscientes de sí mismos y del otro, tuvieron conciencia de su separatividad, y de la diferencia entre ambos, en la medida en que pertenecían a sexo-géneros diferentes. Pero, al reconocer su separatividad, siguen siendo desconocidos, como lo demuestra el hecho de que Adán se defiende acusando a Eva, en lugar de tratar de defenderla. La conciencia de la separación humana, sin la reunión por el amor, es la fuente de la vergüenza, de la culpa y de la angustia. El ser humano de todas las edades y culturas hace frente a la solución de un problema que es siempre el mismo: el problema de cómo superar la separatividad, cómo lograr la unión, cómo trascender la propia vida individual y encontrar compensación. De esta guisa, el amor en sus diversas formas históricas no representaría sino una sutura simbólica a la fractura

${ }_{107}$ Ver G. Simmel, «La aventura», en Cultura femenina..., op. cit., 15 ss.

108 Ver G. Simmel, «Fragment über die Liebe (Aus dem Nachlass)», en SPSG, op. cit., 228.

109 O. PAZ, La llama doble: amor y erotismo, Barcelona, 1993.

${ }_{110}$ Ver E. Fromm, El arte de amar, Barcelona, 1994, 52.

111 Ver G. SimmEL, «Exkurs über den platonischen und modernen Eros», en SPSG, op. cit., 251. 
real de la separatividad. Todo el conjunto de formas históricas que adopta el amor, desde el amor ideal greco-latino, pasando por el amor pasión del siglo XVII, hasta llegar al amor romántico de los siglos XVIII, XIX y XX, no son sino maneras de combatir la propia soledad, aspecto éste cuya forma final no es otra que la propia confrontación con la propia mortalidad y, correlativamente, con el deseo de inmortalidad, que se manifiesta en el amor a los niños como aquella pasión proyectada más allá de la propia muerte ${ }^{112}$. Simmel sitúa su concepción del amor en el seno de su imagen del mundo configurada por las categorías de «más vida» y «más que vida». A la vida, a lo siempre engendrante en algún sentido, le es propio producir más vida, ser más vida; pero también producir al nivel de lo espiritual objetivado algo que es más que vida. La vida saca a partir de sí figuras tanto cognoscitivas como religiosas, tanto artísticas como sociales, tanto técnicas como normativas, que representan un excedente sobre el mero proceso vital y aquello que lo sirve. Crear a partir de sí aquello que ya no es ella misma es lo propio de la vida. Esta trascendencia, esta relación, del espíritu como producción, armonía, contacto, correlación y lucha, con aquello que está más allá de él, es lo que da origen al amor, que, por una parte, está psicológicamente implicado en un desplazamiento continuamente mediado e incierto de la vida y que, por otra parte, en la inmanencia de su propia autorreferencialidad trasciende a la vida, como el conocimiento lógico trasciende al proceso psíquico de ideación, o como la relación estética a valores trasciende a los movimientos psicológicos con los que es creada o disfrutada ${ }^{113}$. El amor determina su objeto en su ser total y final, por cuanto que lo crea como objeto previamente no existente. Así como yo mismo en tanto que amante soy otro que antes de amar (pues no ama esta o aquella de mis "partes» o energías, sino el individuo en su totalidad), así también el amado es, como tal, un ser distinto, que se eleva a partir de otro a priori. Las expresiones de éxtasis del amante no hacen sino confirmar este presupuesto: que el amado "lo es todo en el mundo", que "excepto él nada hay» y otras similares sólo significan esta exclusividad del amor. Pero el amor conlleva un rasgo trágico, como una forma simbólica a la que trasciende la vida, puesto que existe una paradoja entre el inseparable permanecer en el interior del sentimiento de su portador y el abarcar al otro, entre el introducirse en sí y el desear fusionarse en el proceso donde confluyen el yo y el tú, proceso éste al que no se puede garantizar una continuación ininterrumpida.

Para Simmel, ha habido una importante evolución de la semántica del amor, y en este sentido nos ofrece una exquisita comparación entre el amor platónico y el amor moderno ${ }^{114}$. La imagen del mundo del griego estaba basada en la idea de ser (algo inmutable, autosuficiente, perfecto, bello e inteligente),

112 Ver G. Simmel, op. cit., 252.

113 Ver G. Simmel, «Fragment über die Liebe», op. cit., 237-238.

114 Ver el citado artículo de SimMEL, «Exkurs über den platonischen und den Modernen Eros», op. cit., 248-264. 
de un cosmos real unificado, cuya representación plástica autocontenida él reverenciaba como divina. Platón traspone todo valor y toda realidad actual de las cosas al mundo de las ideas, es decir, de las sustancias metafísicas que son las contrapartes metafísicas de nuestros conceptos de las cosas, portadores de la verdad que los trasciende. Si ahora, como es autoevidente para Platón, la belle$z a^{115}$ de una persona nos lleva a amarla, esto es así debido a que despierta en nosotros la memoria de aquella idea de belleza vista por nosotros anteriormente, de aquella imagen original de lo bello en general, de la que conservamos dentro de nosotros un eterno anhelo aquí abajo, producto de nuestras existencias anteriores. El griego, tanto en el pensamiento como en el sentimiento, inevitablemente confronta la existencia dada de alguna manera, pero él siempre imita o sólo reconfigura lo que es dado. Los contenidos del alma están presentes en el griego en cuanto que son traídos de algo ya existente, no en cuanto producidos dentro del alma humana creativa. Mientras que para nosotros el amor sólo es una mediación entre dos personas, Platón traslada el efecto mediador más allá de las relaciones interpersonales y le asigna una relación con lo supraindividual. Para nosotros, la belleza de la individualidad y la individualidad de la belleza constituyen una unidad indivisible; sin embargo, belleza e individualidad son perfectamente separables para Platón. En la interpretación platónica, el amor queda adjuntado a una propiedad nombrable de su objeto, a la belleza, que es concebida como estrictamente universal, equivalente en todas sus manifestaciones. Para nosotros, sin embargo, el misterio último del amor reside en el hecho de que no existe un atributo singular que sea responsable de él, como lo ha puesto de manifiesto el maestro Eckhart cuando, respecto a Dios, afirma que no debiéramos amarlo por poseer este o aquel atributo, sino más bien por ser lo que es. Por mucho valor que puedan tener las cualidades de una persona, los sentimientos son adjuntados a la unidad y totalidad que subyace tras ellos. Su superioridad sobre todos los atributos particulares que estimulan el amor es evidente por el hecho de que el amor sobrevive a la desaparición de tales atributos. La individualidad tiene una significación negativa para Platón porque no capta el sentido del amor como el lado de una relación existente en el sujeto que sólo se completa realmente con el otro lado de la relación existente en otro sujeto; tal relación se basa en la interacción entre amor y contraamor, algo que no puede ofrecer la supraindividualidad divina, por ser autosuficiente. El amor griego es un deseo de posesión, en el más noble sentido de la palabra, por supuesto; poseer en el amado un recipiente para la instrucción ideal y la cultivación moralmente edificante. Para él, el amor puede ser un estadio intermedio entre la posesión y la no-posesión; por tanto, el amor tendría que extinguirse una vez que el estado de posesión se ha alcanzado. Frente a esta posición, el objetivo real del amor moderno es el amor reciproco, cuya expresión más elaborada viene dada por el amor romántico. El objeto

115 El análisis de Simmel se refiere a El Banquete o de la Erótica, incluido en Platón, Diálogos, México, D.F., 351-386. 
del amor platónico no es la mujer, sino el joven, representado arquetípicamente en la figura de Alcibíades. Si la capacidad para el desarrollo intelectual se le ha atribuido al hombre, si éste es portador de la capacidad para el pensamiento abstracto, no debe sorprender situar la belleza suprema en un portador, la juventud masculina. Cuando los hombres se expresaban en relación con las mujeres, lo hacían para estigmatizar sus vicios; de Aristófanes a Séneca, de Plauto a los predicadores cristianos, domina una tradición de diatribas y de sátiras contra la mujer, presentada como ser engañoso y licencioso, inconstante e ignorante, envidioso y peligroso, mitad maldita de la humanidad, bruja. La mujer se presenta (por el hombre) como mal necesario encasillado en las actividades sin brillo, ser inferior sistemáticamente desvalorizado o despreciado por los hombres ${ }^{116}$.

Pero la configuración del amor romántico no es algo que suceda de forma automática a la concepción clásica greco-latina, sino que tiene una génesis social, es decir, los cambios en la estructura social condicionan la metamorfosis en la semántica del amor. A partir del siglo XVIII, el tránsito de un tipo de diferenciación social de tipo estratificacional a una diferenciación funcional basada en el desencantamiento de la jerarquía como principio de orden obliga a una nueva forma de inclusión social, lo más amplia posible, de todas las capas de la población y de todos los ámbitos funcionales. La evolución social tiene que hacer frente a dos pretensiones contradictorias que conformarán la específica temporalización o historicidad de las diversas formas de amor: por una lado, debe hacerse posible lo particular, lo improbable; pero, por otro lado, debe hacerse alcanzable para todo el mundo ${ }^{117}$.

El desarrollo del platonismo en el Renacimiento pretende conectar su naturaleza metafísica con el individualismo en cuyo nombre el Renacimiento ha triunfado, frente al ideal supramundano de la Edad Media. Ahora, no es ya la idea general de la Belleza la que es comtemplada en el «ámbito supercelestial», sino la persona individual misma. Ya no se trata de la imitación de un universal impersonal por la personalidad individual, como ocurría en Platón, sino más bien la elevación de una forma mundana a una trascendente, como en el retrato que realiza Petrarca de Laura de Simone Memmi o en la amada esposa de Miguel Ángel. Esta forma ideal contiene eso que es más que vida. Esta inserción final medieval o protorrenacentista, lejos de entonar la eterna cantinela de las invectivas dirigidas a las mujeres, ensalza modélicamente su papel y sus poderes. Se declara al «bello sexo» como más próximo a la divinidad que el hombre, y se exalta a la madre en efusiones líricas. De Agrippa a Michelet, de Novalis a Bretton, de Musset a Aragon, nunca la mujer fue tan venerada, adorada e idealizada. "El encarnizamiento despreciativo tradicional se ha visto

116 Ver G. LipOVETSKY, La tercera mujer, Barcelona, 1998, 216.

117 Ver N. LuHMANN, «Interaktion im Oberschichten: Zur Transformation ihrer Semantik im 17. Und 18, Jahrhundert", Gesellschaftsstruktur und Semantik, Frankfurt, vol. 1, 1980, $72-161$. 
sucedido por la sacralización de la mujer ${ }^{118}$. La mujer aparece ahora como potencia civilizadora de las costumbres, dueña de los sueños masculinos, «bello sexo», educadora de los hijos, "hada del hogar».

La semántica del amor experimenta otra transformación en la segunda mitad del siglo XVII para pasar de lo ideal a lo paradójico ${ }^{119}$. En el siglo XVII el ideal se convirtió en muletilla retórica. El paso a lo paradójico perfeccionó el proceso de disolución del antiguo contraste entre lo supraindividual y lo individual, entre el amor "elevado" y el amor "profano-pecaminoso", e inició la inclusión de la sexualidad en el amor como algo fundamental para éste. En el siglo XVII, y especialmente en Francia, surgieron importantes aportaciones a la semántica del amor pasional (amour passion), entre las que cabe destacar: la lírica amorosa antigua y la lírica amorosa árabe, los cantos de los bardos del Medievo, la rica literatura amorosa del Renacimiento italiano, etc. La belleza aparece destronada por el amor pasional, y el fundamento de éste radica en la libertad. Mediante su inclusión en lo paradójico se modifica la posición semántica del amor: no se sufre porque el amor sea pecaminoso y despierte apetitos terrenales, se sufre porque el amor no se ha cumplido plenamente, o cuando esa realización no aportó todo lo que prometía. En lugar de una jerarquía de las referencias mundanas del ser humano, se sitúa la legitimidad del amor en un campo vital y experimental relativamente autónomo en el que las distintas paradojas presentes en el amor —autosumisión conquistadora, ceguera que ve, enfermedad deseada, prisión voluntaria o dulce martirio- conducen a la tesis central: la desmesura, el exceso.

A partir del siglo XVIII, el amor romántico se superpone al amor pasión en dos aspectos fundamentales: mediante la inclusión de una individualidad que puede crecer ilimitadamente, y con vistas a la duración, a la conciliación con el matrimonio. Como afirma Niklas Luhmann: «el amor (romántico) se convierte en la base del matriminio y vuelve a ser, de nuevo, mérito del amor (en este caso reflexivo) ${ }^{120}$. El amor se dirige a un yo y un tú, en tanto que ambos están en relación amorosa, es decir, tal relación se hace posible alternativamente y no porque sean buenos, hermosos, nobles o porque sean ricos. El «amor por amor» se convierte en la nueva fórmula existencial y Jean Paul en su más impresionante profeta. El amor romántico introduce la idea de una narrativa en la vida individual, una fórmula que extendió radicalmente la reflexividad del amor sublime. El contar una historia es uno de los significados del «romance», pero esta historia deviene individualizada ahora, insertando a ego y a alter en una narrativa personal que no constituye ninguna referencia particular para procesos sociales más amplios. El surgimiento del amor romántico coincide con la emergencia de la novela. El amor no debe ser visto como una práctica,

118 Ver G. LipOVETSKY, op. cit., 217.

119 Ver al respecto N. LuHmann, El amor como pasión. Codificación de la intimidad, Barcelona, 1985,48 ss.

${ }^{120}$ N. Luhmann, op. cit., 151. 
como una mera relación física entre dos personas; la historia del amor es también la historia de un género literario. El amor romántico o "amor a primera vista» debe ser separado de las compulsiones sexuales y eróticas del amor pasión. Los ideales del amor romántico afectan más a las aspiraciones de la mujer que a las del hombre; por una parte, han contribuido a situar a la mujer «en su sitio", es decir, en el hogar, y, por otra parte, sin embargo, el amor romántico puede ser visto como un cuestionamiento activo y radical de la «masculinidad» de la sociedad moderna. La emergencia del amor romántico es inseparable del surgimiento del estatus de la mujer. No existe amor sin libertad femenina. El amor romántico depende de la capacidad de la mujer no sólo para atraer, sino para elegir y rechazar, convirtiéndose en persona en sentido propio $^{121}$. "Presupone que un vínculo emocional duradero puede ser establecido con el otro sobre la base de cualidades intrínsecas a tal vínculo. Es el heraldo de una relación pura, a pesar de estar en tensión con ella» ${ }^{122}$.

Durante la modernización del Estado de Bienestar, después de la Segunda Guerra Mundial, ocurren dos cosas que afectan al estatus de la mujer: por un lado, las exigencias de la biografía normal y dependiente del mercado se extienden también al contexto de vida de las mujeres y, por otro lado, sin embargo, se crean unas situaciones totalmente nuevas en el seno de las familias y entre hombres y mujeres, hasta el punto de disolver los patrones masculinos de la vida de la sociedad industrial ${ }^{123}$. Más libertad para ambos sujetos del amor y de sexualidad puede producir, y de hecho produce, más inseguridad para ambos ${ }^{124}$. Esta «liberación» de los roles dependientes de la mujer se caracteriza por:

a) Una «liberación demográfica de las mujeres» ${ }^{125}$, ya que si en décadas anteriores el margen de vida de una mujer abarcaba justo lo suficiente para parir y educar el número socialmente "deseado» de hijos que sobrevivían, ese «estar-para-los-hijos» se ha convertido en un período transitorio de la vida de la mujer, ya que después de criar a los hijos todavía le quedan muchos años de vida y de opciones de vida.

b) El aislamiento y la automatización, juntos, provocan una «descalificación del trabajo doméstico» (Claus Offe) que remite a las mujeres que buscan una vida plena al trabajo profesional fuera de casa.

121 O. PAZ, op. cit.

122 A. Giddens, The Transformation of Intimacy. Sexuality, Love and Eroticism in Modern Societies, Stanford, California, 1992, 2, 38 ss.

123 Ver U. BeCK y E. BeCK-Gersheim, El normal caos del amor, Barcelona, 1998, 54. Ver también el interesante artículo de E. BECK-GERSHEIM, «On the Way to a Post-Familial FamilyFrom a Community of Need to Elective Affinities», en Theory, Culture and Society, vol. 15, núms. 3 y 4, 1998, 53-71.

124 E. Gil CALvo ha planteado de manera acertada las consecuencias involuntarias de tales transformaciones en la estructura social y en las correlativas semánticas del amor que afectan a la mujer (ver La mujer cuarteada, Barcelona, 1991) y al hombre (ver El nuevo sexo débil. Los dilemas del varón postmoderno, Barcelona, 1997).

125 Ver A. E. IMHOF, Die gewonnenen Jahre, Munich, 1981. 
c) Los hijos son en principio deseados y la maternidad es una maternidad deseada. La emergencia de lo que Giddens ha llamado "sexualidad plástica»" ${ }^{126}$ supone un descentramiento de la sexualidad, liberada de las necesidades de la reproducción. Tiene su origen en la tendencia ya iniciada en el siglo XVIII de reducción del tamaño de la familia, pero se desarrolla más tarde con la extensión de la contracepción y las nuevas tecnologías reproductoras. Al mismo tiempo libera a la sexualidad del dominio del falo, de la sobrevalorada experiencia sexual masculina. Incluso el macho gay, la leather queen o el denim groupie no son sino réplicas irónicas de la masculinidad heterosexual, son deconstrucciones visibles de la masculinidad, y al mismo tiempo afirman aquello que el poder fálico dado por supuesto denegaba: que, en la sociedad moderna, la identidad, incluida la identidad sexo-género, es un logro reflexivo. Incluso podemos distinguir un giro postmoderno de esta "sexualidad plástica» según el cual el "estar en forma», cuya variante sexual sería la sexualidad que conduce al orgasmo, algo que se puede conseguir con los gadgets, el entrenamiento o las drogas, como la Viagra, representa el triunfo de la sensación, la inmediatez y la apariencia física; si tienes buen aspecto, te sientes bien ${ }^{127}$. En un mundo de extranjeros el aspecto físico se convierte en un pasaporte importante para participar en el intercambio simbólico y en el mercado de emociones libres, tanto en lo relativo a la atracción sexual como en lo relativo al deseo erótico.

d) Las mujeres hacen uso del derecho al divorcio para romper situaciones no basadas en el amor romántico ${ }^{128}$.

e) Los efectos de la igualdad en la enseñanza van en la misma dirección y expresan también la fuerte motivación profesional de las mujeres jóvenes.

El hombre, en el ensamblaje de los roles tradicionales de género, sólo era el amo libre de trabajo doméstico, pero tiene que ejercer de esclavo para ganarse la vida. Su posición de fantasma en la familia presupone que debe soportar el trabajo remunerado. Sólo en el lecho matrimonial podía disfrutar a lo que apuntaba el centro secreto de sus deseos, llamado "pene» por la medicina. Pero el camino hacia tal lecho pasaba por la entrada en la fábrica y las cargas físicas y simbólicas que el hombre tenía que asumir y soportar. La sexualidad y el amor ya no van ligados al matrimonio y al sustento económico de la esposa. Si el hombre así lo quiere, puede decir: amor y sexualidad sí, matrimonio no. Y con esto aun le hace un favor a la emancipación de las mujeres. La vida en pareja, la sexualidad, el amor, la ternura, se liberan de las cadenas del matrimonio, ya en interés propio de la mujer. Esto sigue siendo todavía amor romántico excepto por haber cortado las amarras que unían a ambos amantes matrimonialmente. Los hombres promueven la emancipación de la mujer en lugar de

126 A. GIDDENS, op. cit., 2-3, 87 ss., 134 ss.

127 Z. Bauman, "On the Postmodern Uses of Sex", en Theory, Culture and Society, vol. 15, núms. 3 y 4, 1998, 23 ss.

128 Ver BeCK y BeCK-Gersheim, op. cit., 59. 
su propia autoliberación, por decirlo así; hoy desde el asiento del espectador impulsan su "autoliberación», elogiando perplejos, pero con benevolencia, la salida de la mujer de su rol cuasinaturalizado. Su emancipación —su liberación del yugo de sustentador de la familia - les cae del cielo como una manzana madura, "la manzana tardía de Eva» ${ }^{129}$. Ésta no deja de ser una emancipación involuntaria, más «sufrida» que deseada por el hombre.

Vemos que después de mundanizar la relación amorosa, supraindividualmente considerada por los griegos y la patrística cristiana, todavía persiste ese rasgo trágico del amor incluso en su forma más moderna de amor romántico sexualizado y que vuelve a retrotraernos a la dialéctica tan simmeliana entre más vida y más que vida.

\section{CONCLUSIONES}

En la labor de interpretación sociológica que hemos realizado a lo largo de estas páginas, siguiendo con paciencia el sendero conceptual simmeliano, hemos logrado arribar al desocultamiento del ser femenino o de la constelación femenina que permanecía «oculta» en el seno de la cultura objetiva. Hemos comenzado determinando el marco conceptual y cosmovisional que sirve a Simmel para interpretar la naturaleza y la génesis de tal constelación femenina. Veíamos que los individuos son trascendidos por las formas por ellos/ellas creadas, es decir, por lo que Simmel ha llamado "cultura objetiva»; pero, al mismo tiempo, la vida (el engendrador de todo engendro, el cambio, eso que es incambiable, la creatividad inscrita en el alma humana) trasciende asimismo las formas culturales cristalizadas en la conciencia colectiva. "Más vida» y "más que vida" no son sino esos dos grandes movimientos que determinan la existencia humana en su sentido más radical y auténtico.

En este dualismo entre vida y forma, la cultura objetiva ha logrado imponerse como una forma con un patrón característico que opera «en el nombre del padre», se ha producido una yuxtaposición de los valores masculinos con los valores en general producto de relaciones históricas de poder, como advierten Simmel, Foucault y toda la crítica feminista contemporánea. Se ha identificado lo objetivo con lo masculino, es decir, se ha entronizado toda la constelación de valores masculina, representada por el hacer, la justicia abstracta, la especialización, el distanciamiento y la despersonalización, como la estructura de valores dominante, subjerarquizando y ocultando "la otra cultura», la femenina, identificada con el ser, el cuidado y el afecto, la uniformidad, la integración y la personalización. Estas dos constelaciones son dos posibilidades, dos tipos de personalidad, dos tipos de "sí mismo" institucionalizados de forma desigual. Aquí radica el interés de la labor simmeliana de desocultamiento de la trama de significación implicada en tal cultura objetiva (capitalista tardía) y

129 Ver BeCK y BECK-GERSHEIM, op. cit., 269-276. 
su interés por la "cultura femenina», a diferencia de las posiciones liberal y socialista, a las que considera una esperanza contra la alienación de la subjetividad viva con respecto a las inertes objetivaciones de una «cultura masculina del trabajo» que, como hemos visto, ha reivindicado injustamente la exclusiva de lo humano en general.

En esta genealogía crítica de la femineidad, Simmel va a partir del supuesto que el sujeto no es su propio punto de partida, sino que el sujeto es algo así como el efecto de una "carrera moral», el llegar a ser sujeto generizado es siempre un hacer. No existe identidad de género antes de las expresiones del género, la identidad es performativamente constituida por tales "expresiones» que proclaman ser sus resultados. En este sentido, Simmel presenta una serie de actos performativos que conforman una fenomenología inmanente en la que se producen una serie de actuaciones como la prostitución, la coquetería, la moda y la aventura, a través de las que el género se in-corpora y el cuerpo se generiza, conformando una matriz (no patrón) cultural femenina con sus propios principios de organización de la experiencia dentro de la cultura objetiva.

En su análisis del amor y la sexualidad, Simmel manifiesta asimismo la constitución histórica del sujeto femenino través de una lucha por el reconocimiento. Comparando el amor clásico con el moderno, Simmel señala que el objetivo real del amor moderno es el amor recíproco entre sujetos libres, cuya expresión más elaborada viene dada por el amor romántico que conecta el amor y la sexualidad, frente al amor a algo supraindividual propio de los griegos.

\footnotetext{
ABSTRACT

This papper focuse on the analysis of the «femenine culture» in the work of Georg Simmel, taking into account its hidden being within the objective culture, predominantly masculine. Aspects like gender, love and sexuality are considered assuming the contributions made by the contemporary social critique represented by Goffman, Foucault, Benhabib, Butler and Beck.
} 
NOTAS DE INVESTIGACIÓN 